REYISTA

dete

CEPA

NUMERO 62

AGOSTO 1997

SANTIAGO DE CHILE

OSCAR ALTIMIR

Direcsor

EUGENIO LAHERA

Secretario Técnico

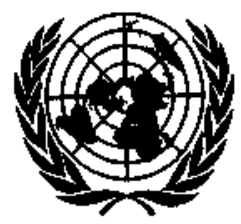

NACIONES UNIDAS 
Estado, comunidad y sociedad en el desarrollo social

Fermando Henrique Cardoso

Un balance de las reformas estructurales neoliberales en América Latina

Joseph Ramos

Deuda y sostenibilidad ffscal: ise repite la historia?

Guillermo E. Perry

Reformas petroleras: las opciones en juego

Fernando Sánchez Albavera

Las organizaciones indígenas: actores emergentes en

América Latina

Rodolfo Stavenhagen

El empleo rural no agropecuario en el Istmo Centroamericano

Jürgen Weller

Marginalidad e integración social en Uruguay

Rubén Kaztman

La política comercial en el marco de la Organización Mundial

de Comercio

Diana Tussie

Comercio y medio ambiente: ¿luz verde o luz roja?

Helga Hoffmann

Anclas nominales y escenarios de coordinación macroeconómica en el MERCoSUR

Gonzalo Rodríguez Prada

Políticas de promoción de exportaciones en Centroamérica

Larry Willmore

Publicaciones recientes de la CEPAL 


\section{Marginalidad e integración social en Uruguay}

\section{Ruben Kaztman}

Director.

Oficina de la cEMAL

en Montevideo
En el panorama latinoamericano, Uruguay se destaca por su igualitaria distribución del ingreso, la solidez de su democracia y su nivel de integración social. En la última década, sin embargo, ha habido señales de fisuras que enrarecen la convivencia ciudadana. Esas fisuras se manifiestan a través de comportamientos marginales, esto es, comportamientos que no se rigen por los patrones socialmente aceptados. El porqué de tales comportamientos se ha rastreado aquí en los desajustes entre las metas culturales, las estructuras de oportunidades para alcanzar las metas y la formación de capacidades indivjduales para aprovecharlas. Una premisa central del esquema aplicado es que los factores que determinan comportamientos marginales van sumando sus efectos de manera cíclica a lo largo de las etapas de la vida individual y de generación en generación. Dado ese carácter cíclico, toda decisión sobre prioridades al atacar las situaciones de marginalidad es ineficiente sin una mirada de conjunto. De allí que el diseño de una política social integrada que busque recomponer los vínculos de los marginales con la sociedad deberá al menos: i) componer el cuadro más completo posible de situaciones de marginalidad a lo largo de la vida; ii) descubrir en cada etapa las condiciones que ayudan a acumular y consolidar la marginalidad y iii) identificar puntos de intervención que, por su relación costo-beneficio, sean cruciales para romper los eslabones que hacen posible la acumulación individual y la reproducción intergeneracional de situaciones de marginalidad. El artículo pone de relieve las diferencias entre pobreza y pobreza marginal, no porque se asuma que la marginalidad se agota en la pobreza, sino porque es alli donde se concentran las formas de marginalidad de mayor costo individual y social. Se postula que el elemento clave de la diferenciación es el capital social, en cuyo debilitamiento intervienen principalmente la desar. ticulación familiar y procesos de segmentación como la segregación residencial -cuyo extremo son los asentamientos precarios- y el deterioro de la función integradora del sistema educativo. 
I

\section{Introducción}

Son muchas las voces que expresan preocupación ante los indicadores de descomposición social que se ob-. servan en las grandes ciudades latinoamericanas, cuyas señales más notorias son las mayores tasas de delincuencia y el incremento de la violencia, el tráfico de drogas, la drogadicción y la corrupción. Como causas se mencionan factores culturales (el énfasis en el individualismo, en la realización personal, en la privatizacion de la vida y en el consumismo); sociales (el debilitamiento de las instituciones primordiales, familia, barrio, comunidad e iglesia; la creciente segregación residencial y la estratificación del acceso a servicios tásicos), y económicos (principalmente los efectos sobre el empleo de las exigencias de mayor competitividad, causa y efecto de la creciente apertura del comercio internacional).

La consecuencia más clara de la acción de esos factores es el debilitamiento del capital social. Cada miembro de una comunidad tiene un capital social cuyo monto es directamente proporcional tanto a su confianza en que los demás miembros ajustarán su comportamiento a ciertas normas básicas de convivencia, como al grado de legitimidad de sus expectativas de movilizar la voluntad de otros en su beneficio. El desgaste del capital social implica un descenso en la calidad de vida que se refleja, entre otras cosas, en los niveles de inseguridad de la población ante el crimen y la violencia, como lo revelan las encuestas de opinión que se llevan a cabo en algunos centros urbanos de América Latiná.

Fara los observadores externos, Uruguay se presenta como una sociedad con un nivel de integración social muy alto, donde se conjuga una democracia social sólida con una igualmente sólida democracia política. El nivel de integración se manifiesta en el funcionamiento de sus instituciones, en la ausencia de distancias sociales importantes, en la comunicación fluida y simétrica entre personas de distinta extracción social, así como en las múltiples formas en que se expresa la solidaridad social cuando ésta es convocada. Pese a esas características, en las ciudades urugua-

I.] El autor agradece la colaboración estadística de Alvaro Fuentes, así como la infonnación sobre temas específicos suministrada por Mabel Abelia de Mutarelli, Ema Baraibar, Virginia Cura y Eduardo Morás. yas, y en particular en Montevideo, también están surgiendo indicios de los mismos males que aquejan a otros centros urbanos: una elevación considerable del nivel de violencia delictiva y una opinión pública atemorizada que presiona para que el gobierno dé prioridad a la lucha contra la delincuencia. Tanto entre las autoridades públicas como entre los analistas del tema existe la convicción de que tales males están asociados a procesos de marginalización que afectan particularmente a los estratos populares urbanos. Este artículo explora la naturaleza, causas y consecuencias de tales procesos.

Desde el punto de vista de aquellos investigadores, académicos y políticos preocupados por las experiencias de descomposición social en la región, quizás el mayor atractivo del examen del caso uruguayo radique en que la situación general del país permite ser más optimista que en otros casos respecto a la posibilidad de actuar eficazmente sobre el problema. Dicho optimismo se apoya en dos aspectos de la realidad uruguaya: primero, los procesos de marginalización son relativamente incipientes, no habiéndose consolidado todavía el tipo de subculturas marginales que generan tanto su propia reproducción como resistencias estructuradas a su disolución; segundo, las propuestas dirigidas a bloquear las rutas a la marginalidad, frenar el deterioro del capital social y crear o reforzar las instituciones que lo acumulan probablemente tengan una capacidad de convocatoria y movilización mayor que en otros lados.

La importancia de examinar los procesos de marginalización en una sociedad que ofrece expectativas razonables de frenar o revertir dichos procesos debe evaluarse en el marco de una de las preocupaciones centrales de los observadores de la realidad latinoamericana: la constatación de una suerte de desconcierto y desesperanza que inhibe la capacidad de reacción ante el problema; una actitud de "sálvese quien pueda y como pueda" que parece afectar tanto a la ciudadanía en general como a las elites económicas y políticas. Es como si, ante el carácter de inevitable con que se presenta la acción de las fuerzas disolventes, la respuesta generalizada fuera buscar refugio en la vida privada, amurallarse en las viviendas y limitar los movimientos a las zonas "seguras", bajo el convencimiento de que todo intento de frenar o revertir esas 
fuerzas está condenado al fracaso. Si bien no se puede afirmar que tales actitudes y comportamientos estén ausentes en Uruguay, el análisis comparativo con el resto de los países de la región muestra que la sociedad uruguaya cuenta todavía con un sólido capital social, recurso que podría movilizarse para evitar su propio desgaste. Además, es dable presumir que la generación que tiene hoy día en sus manos la conducción del país, todavía asocia en su memoria el alto nivel de integración social que caracterizó a la sociedad a lo largo del siglo con la buena calidad de vida que tuvieron los ciudadanos en ese período. Estos antecedentes permiten abrigar la esperanza de que un diagnóstico oportuno de las características de la marginalidad actual en Uruguay pueda movilizar iniciativas en la dirección correcta, lo que emitiría señales positivas para el tratamiento de problemas similares en otras sociedades latinoamericanas. Este trabajo pretende ser un aporte a ese diagnóstico.

Por la necesidad analítica de acotar el problema, y porque se presume que en los estratos bajos urbanos se concentran las formas de marginalidad de mayor costo individual y familiar, hemos examinado las condiciones que favorecen la emergencia de la marginalidad sólo en los estratos bajos urbanos. La hipótesis de trabajo que orienta la exploración es que el fenómeno responde a una creciente vulnerabilidad de dichos estratos, fruto de la acción combinada de tres procesos: i) un cambio en los patrones de incorporación al mundo del trabajo; ii) un debilitamiento de las estructuras familiares y iii) una creciente segmentación social que se traduce en aislamiento con respecto al resto de la socjedad. La concentración en los estratos bajos urbanos no implica negar la importancia de otras formas de marginalidad ni tampoco la significativa contribución que ellas hacen a la desintegración social (la consideración de los problemas de corrupción sugiere que en muchos países son otros los estratos que están haciendo el mayor aporte a la desarticulación social).
En este artículo se analiza en primer lugar el cambio en la frecuencia y nivel de violencia de los comportamientos delictivos como señal de fisuras en la sociedad. Se examina la relación entre las variaciones en los delitos y el sentimiento de inseguridad de la población, destacando la posible incidencia de un mecanismo perverso por el cual la criminalidad alimenta la inseguridad y ésta, a su vez, genera conductas que debilitan el tejido social.

Enseguida se pasa revista a las peculiaridades de la marginalidad en el Uruguay de hoy, distinguiéndola de la pobreza así como de formas de marginalidad que afectaron a la región en décadas pasadas. Se señala que uno de los motores de la marginalidad actual es un desajuste entre las metas, los medios y las capacidades para hacer uso de éstos. En particular, se destaca la importancia del desajuste entre la estructura productiva y la estructura familiar, que debilita la capacidad de las familias de proveer los activos que necesitan las nuevas generaciones para incorporarse a los canales de movilidad social de la sociedad moderna.

Luego se escudriña la relación entre familia. marginalidad y comportamientos delictivos, utilizando para ello datos sobre antecedentes familiares de menores ingresados al Instituto Nacional del Menor (INAME) por "infractores" o por "inconducta social". Las conclusiones de este análisis apuntan a la importancia de las formas inestables e incompletas de familia, por lo que se investigan dos factores asociados a esos fenómenos: los cambios en la sexualidad adolescente y la renuencia de los varones jóvenes de estratos bajos urbanos a constituir nuevos hogares.

Se argumenta en seguida que los procesos de segregación residencial y de segmentación de los servicios, sobre todo en la educación, refuerzan las tendencias a la marginalidad. $Y$, por último, se presentan las conclusiones del análisis y algunas líneas generales de acción tendientes a bloquear las rutas a la marginalidad.

\section{II}

\section{Uruguay en el contexto latinoamericano}

La comparación de los índices de pobreza y de concentración del ingreso de Uruguay con los de los restantes países de la región, particularmente los que tienen ingresos per cápita de nivel similar, muestra una sociedad con un grado de equidad relativamente alto (cuadro 1). Enraizados en las instituciones, los criterios de equidad han servido de base a una democracia social efectiva que se refleja, entre otras cosas, en la 
CUADRO I

América Latina: Indicadores de las condlciones de vida, alrededor de 1992

\begin{tabular}{lccc}
\hline Países & $\begin{array}{c}\text { PIB } \\
\text { por habitante } \\
\text { (dílares de } 1980 \text { ) }\end{array}$ & $\begin{array}{c}\text { Hogares bajo } \\
\text { la línea de } \\
\text { pobreza }(\%)\end{array}$ & $\begin{array}{c}\text { Coeficiente } \\
\text { de Gini }\end{array}$ \\
\hline Argentina (1992) & 3757 & 13.5 & 0.408 \\
Bolivia (1992) & 685 & 46 & 0.478 \\
Brasil (1990) & 1916 & 50 & 0.535 \\
Chile (1994) & 3172 & 24 & 0.479 \\
Colombia (1992) & 1474 & 38 & 0.454 \\
Costa Rica (1992) & 1523 & 25 & 0.362 \\
Guaternala (1990) & 923 & $\ldots$ & 0.479 \\
Honduras (1992) & 662 & 66 & 0.461 \\
México (1992) & 2558 & 30 & 0.414 \\
Panamá (1991) & 1657 & 34 & 0.448 \\
Paraguay (1992) & 1265 & $\ldots$ & $0.39 !$ \\
Perú (1986) & 1107 & 45 & \\
Uruguay (1992) & 2480 & 8 & 0.301 \\
Venezalela (1992) & 3644 & 32 & 0.380 \\
\hline
\end{tabular}

Fuente: CEPAL, 1995. simettra del trato cotidiano y en la falta de barreras para la comunicación fluida entre personas de distinta con. dición económica.

La democracia social fundamenta y dinamiza a su vez una democracia política cuya solidez singulariza al Uruguay en la región. Así lo ilustran las respuestas a una serie de preguntas que se realizaron en ocho paises latinoamericanos y que estuvieron dirigidas a indagar la fortaleza de la democracia a través del respaldo que le presta la ciudadanía a sus instituciones centrales (cuadro 2): los uruguayos obtuvieron el mayor puntaje, expresado como la suma de los porcentajes de respuestas positivas sobre rasgos del funcionamiento de la democracia en los respectivos países.

El perfil trazado, que combina equidad con democracia, es propio de una sociedad con altos niveles de integración. $Y$ así ha sido caracterizada la sociedad uruguaya en el marco latinoamericano.

CUADR1) 2

América Latina (ocho pafses): Opiniones sobre democracia, 1995

(\% que responde afirmativamente)

Argentina Brasil Chile México Paraguay Perú Uruguay Venezuela

1. La democracia es preferible a cualquier otra forma de gobierno

\begin{tabular}{rrrrrrrr}
82 & 48 & 54 & 57 & 58 & 58 & 86 & 64 \\
53 & 31 & 34 & 24 & 31 & 47 & 59 & 38 \\
59 & 51 & 51 & 52 & 39 & 71 & 63 & 53 \\
78 & 26 & 82 & 13 & 10 & 64 & 83 & 19 \\
42 & 27 & 48 & 31 & 56 & 45 & 57 & 40 \\
19 & 16 & 24 & 24 & 28 & 29 & 38 & 16 \\
75 & 53 & 56 & 53 & 62 & 75 & 77 & 52 \\
408 & 252 & 349 & 254 & 284 & 389 & 463 & 282 \\
\hline
\end{tabular}

2. Sarisfacción con el funcionamiento de ta dennociacia en el país

3. La desnocracia permite que se solucionen los problemas del país

4. LAs elecciones en el país son limpias

5. Todos los grupos y partidos políticos tienen iguales oportunidades de dar a conocer sus opiniones en televisión

6. Los senadores y diputados se preocupan de lo que piensa la gente como uno

7. La manera como uno vota puede hacer qu: las cosas sean diferentes en el futuro

Total

Fuente. Elaboración propia sobre la base de Basínez, Lagos y Beltú́n, 1996. 


\section{III}

\section{Señales de fisuras en un tejido social integrado: El avance de la criminalidad en Uruguay}

\section{Inseguridad pública ${ }^{1}$}

Más allá de lo que registran las estadísticas sobre delincuencia, drogadicción y actos de violencia, la generalidad de los residentes de las grandes ciudades latinoamericanas está de acuerdo en que en los dos últimos decenios se produjeron cambios importantes en los patrones de convivencia de la sociedad civil. Así lo manifiesta una gran mayoría de los que responden a encuestas de opinión, que declara percibir un aumento significativo de conductas antisociales como la delincuencia, la violencia, la drogadicción y la corrupción (cuadro 3). Una mayoría similar expresa desconfianza en las instituciones cuya función es controlar dichas conductas, como la policía y el poder judicial (Basáñez, Lagos y Beltrán, 1996).

La relativa equidad de la estructura social uruguaya no le ha permitido eludir estos problemas. Es notable la unanimidad con que la opinión pública percibe un agravamiento en los últimos años de los problemas mencionados (cuadro 3). Si bien, como veremos más adelante, podría ponerse en duda el nivel de realismo

CUADRO 3

Uruguay: Opiniones sobre la evolución de algunos problemas sociales, 1995

\begin{tabular}{lcccc}
\hline & \multicolumn{4}{c}{$\begin{array}{c}\text { Porcentaje que cree que en los } \\
\text { ultijnos cinco affos: }\end{array}$} \\
\cline { 2 - 5 } $\begin{array}{l}\text { Problemas } \\
\text { sociales }\end{array}$ & $\begin{array}{c}\text { Han } \\
\text { aumentado }\end{array}$ & $\begin{array}{c}\text { Se han } \\
\text { mantenido } \\
\text { igual }\end{array}$ & $\begin{array}{c}\text { Hail } \\
\text { disminuido }\end{array}$ & $\begin{array}{c}\text { Total } \\
\%\end{array}$ \\
\hline $\begin{array}{l}\text { Narcotráfico } \\
\text { Delincuencia }\end{array}$ & 87 & 12 & 2 & 100 \\
Drogadicción & 90 & 9 & 1 & 100 \\
Corrupción & 93 & 7 & 1 & 100 \\
\hline
\end{tabular}

Fuente: Elaboración propia sobre la base de Basáñez, Lagos y Beltrán, 1996.

I Ciertamente son muchas las fuentes de inseguridad en la sociedad actual, siendo particularmente importantes las relacionadas con el debilitamiento de marcos normativos tradicionales y las incertidumbres con respecto al empleo y a los ingresos. Sin embargo, el tếrmino "inseguridad páblica" será usado en este texto para hacer referencia sólo a aquella que surge como respuesta al crimen y a la violencia. tras esas opiniones, el alto grado de consenso entre ellas revela la existencia de un fenómeno social -en la medida que modela actitudes y determina comportamientos- cuya importancia no se puede negar. Los sondeos indican también una baja aprobación de las instituciones encargadas de ejercer el control del comportamiento delictivo. El $41 \%$ de los entrevistados tiene poca o ninguna confianza en el Poder Judicial, elevándose esta cifra al $51 \%$ en el caso de la policía. ${ }^{2}$ Otra fuente registra una mayor frecuencia de opiniones negativas sobre estas instituciones, con un $53 \%$ de los entrevistados que declara que confía poco o nada en los jueces y un $71 \%$ que tiene la misma opinión sobre los policías. ${ }^{3}$

Esta combinación de juicios que afïrman un incremento de conductas delictivas y una baja confiabilidad de las instituciones de control, no puede menos que desembocar en un sentimiento generalizado de inseguridad. Según una encuesta de junio de 1995 , dicho sentimiento aquejaba a un $62 \%$ de los montevideanos y a un $34 \%$ de los habitantes del interior del país. ${ }^{4}$

También ayuda a comprender por qué los uruguayos ubican el tratamiento de la delincuencia entre las acciones prioritarias a las que se debe abocar el gobierno. Según sondeos de opinión, a partir de 1994 la delincuencia figura como el principal problema de los uruguayos. En una medición de abril de 1996, el por-

\footnotetext{
${ }^{2}$ Basáínez, Lagos y Beltrán, 1996. Esta encuesta muestra la escasa confianza en la policía y la justicia en los ocho países latinoamericanos considerados. Uruguay es claramente el pás donde la justicia tiene mayor nivel de aprobación. En el resto, la "poca/nada confanza" en el Poder Judicial es considerablemente superior, alcanzando el nivel de desaprobación míníno en Chile y Brasit con 59\% y el máximo en Perú, con $73 \%$. Respecto a la policía, los datos muestran en Chile un $36 \%$ de desaprobación y en el resto de los países, exceptuado Uruguay, cifras superiores al 58\% de "poca/nada confianza" en esta institución. Pese al mayor nivel rélativo de opjniones favorables en Uruguay, es preocupante que cuatro de cado diez en et caso de la justicia y algo más de la mitad en el caso de ta policta, expresen baja o ninguna confianza en esas instituciones. ${ }^{3}$ Medición realizada por cifrNGonzález, Raga y Asociados (El pús, 1995).

“Encuesta de cifrNGonźlez, Raga y Asociados (El pats, 1995). La pregunta formulada era: Si su farnilita llega de noche tarde a su casa: ¿se siente seguro o inseguro?
} 
centaje de personas que declaran que la delincuencia debe figurar en primer lugar entre los problemas del país $(32.4 \%)$ duplica a las que plantean que el problema principal es el empleo (16.2\%). ${ }^{5}$

\section{Cambios en la sociedad derivados del cilma de themor ante la criminalidad y la violencia}

$\mathrm{El}$ aumento del crimen genera temor y, naturalmente, las personas atemorizadas buscan formas de protegerse. Si bien las estrategias difieren, pueden señalarse elementos comunes. Por ejemplo, una mayor sensibjlidad para identificar y eludir lugares y situaciones peligrosas, lo que para los que cuentan con recursos suficientes puede implicar mudarse de barrio; el creciente amurallamiento de las viviendas, y una mayor vigilancia y control de los movimientos de los niños y jóvenes fuera del hogar. La acumulación de comportamientos de este tipo va moldeando nuevos estilos de vida que poco a poco imprimen su huella en el diseño urbano, en la economía y en la estructura social.

\section{a) Estilo y calidad de vida}

Pese a que Uruguay no dispone de estudios específicamente điseñados para investigar tales cambios, hay muestras indirectas de alteraciones en el comportamiento cotidiano de la ciudadanía impulsadas por el temor a la criminalidad. ${ }^{6}$ Los padres acompañan más a sus hijos al colegio o contratan servicios de transporte que los movilicen. Se evita el tránsito nocturno y aun diurno en ciertas calles o barrios, así como portar dinero o artículos de valor. El clima de inseguridad estimula también el esparcimiento privado a través de la televisión y los videos. Como ya se observa en países donde el problema de inseguridad ciudadana es mucho más grave, a largo plazo estas situaciones desalientan la sociabilidad espontánea que surge en encuentros informales en lugares públicos (catés, plazas, clubes, etc.) $y$, en particular, tienden a reducir las oportunida-

\footnotetext{
${ }^{5}$ Encuesta de Vox-Opinión y Mercado (Búsqueda, 1996a). La demanda colectiva de seguridad encontró eco en el sistema político que, con un consenso inusual en la historia del país, manifestó en 1995 la. necesidad de dotarse de instrumentos más efectivos para garantizar la seguridad pública. Ese mismo año, y en una de sus primeras acciones, el Parlamento promovió una nueva Ley de Seguridad Ciudadana, que fue aprobada por la gran mayoría de los legisladores.

- En ura encuesta realizada por el Washington $P_{o s t}$ en Estados Unidos, un $40 \%$ de los respondentes declararon que habian alterado en los viltimos años sus estilos de vida debido a su temor a la criIninalidad (ver UNRISD, 1995, p. 76). Uruguay no ha hecho hasta ahora una indagación similar.
}

CUADRO 4

Uruguay: Registros de armas de fuego, 1944-1995

\begin{tabular}{lccc}
\hline Periodo & $\begin{array}{c}\text { Número de } \\
\text { títulos } \\
\text { registrados }\end{array}$ & $\begin{array}{c}\text { Promedio } \\
\text { anual }\end{array}$ & $\begin{array}{c}\text { Porcentajes } \\
(1944-1972=100)\end{array}$ \\
\hline $1944-1972$ & 157947 & 5446 & 100.0 \\
$1973-1985$ & 92381 & 7106 & 130.5 \\
$1986-1991$ & 115312 & 19219 & 352.9 \\
1992 & & 20017 & 367.6 \\
1993 & & 22279 & 409.1 \\
1994 & & 23893 & 438.7 \\
1995 & 26967 & 495.2 \\
\hline
\end{tabular}

Fuente: Elaboración propia sobre la base de intormación incluida en Klein (1994) y datos del Servicio de Materiales y Armamentos del Ejército.

des de interacción entre personas de distinto origen social.

Tanto por los riesgos que implica como por el grado de temor que refleja, un indicador importante de cambio en el estilo y calidad de vida se vincula con la decisión de adquirir un arma de fuego. Encuestas recientes de opinión pública que cubren el Uruguay urbano revelan que el $40 \%$ de la población considera que "por seguridad" es mejor "tener un arma de fuego en la casa". El 22\% dice poseer un arma en su hogar, mientras que un $12 \%$ la piensa comprar. ${ }^{7}$ Un estudio reciente permite una aproximación a la evolución de la propiedad de armas de fuego a través del tiempo ${ }^{8}$ (cuadro 4). Los datos exhiben con elocuencia el fuerte incremento en los registros de esas armas. Otra señal en el mismo sentido es el aumento del $50 \%$ en el número de socios del Club de Tiro entre principios de 1994 y fines de $1995 .^{9}$

\section{b) Diseño urbano}

Los cambios en los estilos de vida que impulsa el sentimiento generalizado de inseguridad también van modificando la estructura de las ciudades. Por ejem-

\footnotetext{
${ }^{7}$ Segón la encuesta de cifan/Gonzillez, Raga y Asociados (El pais. 1996a).

${ }^{8}$ Klein, 1994. También datos del Servicio de Material y Armamento del Ejército.

${ }^{9}$ Según un informe publicado por Posdata el 5 de enero de 1996. Otra señal de la necesidad percibida de defensa personal es el considerable aumento de la demanda de gases paralizantes. Su importación estuvo prohibida hasta que una disposición del Servicio de Material y Armatnento de marzo de 1993 autorizs su venta al público, lo que se facilitó además porque la compra tanto de los spray como de otros elementos defensivos, como las picanas eléctricas. no requieren de ningún trámite administrativo, y su utilización con fines defensivos tampoco contleva una responsabilidad penal.
} 
plo, suburbios de clase media de Montevideo, que hasta hace pocos años se caracterizaban por sus jardines abiertos, se presentan hoy totalmente enrejados o amurallados. El perfil urbano se ve alterado por el crecimiento de edificios cuya construcción es parcialmente estimulada por el traslado a departamentos de familias que buscan una seguridad que no encuentran en sus casas. Que muchas veces el traslado no tiene el efecto buscado lo pone de manifiesto el creciente número de edificios con balcones enrejados o con cerramientos de seguridad. Las mismas causas están movilizando la oferta de condominios, esto es, grupos de casas cuyos habitantes comparten los gastos de seguridad para proteger una frontera común.

\section{c) Economía}

El clima de inseguridad ciudadana también tiene importantes consecuencias en una serie de aspectos de la economía, como la expansión de los centros comerciales (shopping malls) y el crecimiento de servicios de seguridad y de venta de artículos para la defensa personal.

i) Centros comerciales. El hecho de que éstos publiciten la vigilancia en sus recintos cerrados y en sus estacionamientos como una dimensión destacada de sus servicios sugiere que la oferta de seguridad puede estar contribuyendo a la expansion de este tipo de organizaciones comerciales.

ii) Seguros contra robos. De acuerdo a datos aportados por el Departamento de Cauciones del Banco de Seguros del Estado, en 1985-1994 la cantidad de pólizas emitidas y primas contratadas correspondientes a contratos de hurto e incendio de vivienda y comercio aumento en $30 \%$ anualmente.

iii) Agencias de vigilancia. Como se mencionó anteriormente, los sondeos de opinión pública registran una baja aprobación de las instituciones encargadas de ejercer el control social. La percepción sobre ta ineficiencia de las agencias estatales de esta índole para hacer frente al auge delictivo explica la frecuencia con que las personas recurren a la contratación privada de seguridad. En 1991 existían 96 empresas registradas. Este número se elevó a 147 en 1993 y a 185 en mayo de $1995{ }^{10}$ Un informe de la Cámara Uruguaya de Empresas de Seguridad da cuenta de la proyección social y económica del sector: aproximadamente 6500 perso-

\footnotetext{
* Según datos oficiales provenientes del Registro Nacional de Empresłs de Seguridad dependjente de la Dirección Nacional de Inteligencia.
}

nas empleadas y aportes fiscales por alrededor de 24 millones de dólares al año.

iv) Comercio de artículos de seguridad. Prosperan las empresas que ofrecen artículos de seguridad: alarmas para automóviles, casas y establecimientos de todo tipo; dispositivos electrónicos de vigilancia, armas, elementos para la defensa personal, etc.

En suma, si se mide por la tasa de crecimiento de sus actividades, los servicios de seguridad se han convertido, en un corto plazo, en uno de los sectores económicos más pujantes y de mayor capacidad de absorción de innovaciones tecnológicas.

\section{d) Estructura social}

Todos estos cambios tienen consecuencias sobre el nivel de integración de la sociedad que se traducen en la aparición de nuevos clivajes, de desestímulos a la inversión en capital social y de un aumento de la distancia social entre estratos socioeconómicos distintos.

i) Nuevo clivaje social. Los miembros de distintos estratos socioeconómicos tienen desigual acceso a bienes y servicios para su defensa y la de sus familias. Siendo la seguridad ante el crimen y la violencia un bien que cobra importancia creciente en la vida de las personas, las diferencias entre los hogares que pueden y los que no pueden garantizar para sí una protección razonable contra actos criminales, así como un resarcimiento adecuado por los daños materiales que éstos provocan, crea una nueva e importante dimensión en la estratificación de las sociedades urbanas modernas: el nivel de satisfacción de las demandas de seguridad.

ii) Interés en atacar las causas del problema. Parece razonable pensar que cuanto más fácil sea el acceso a alternativas privadas de seguridad, menor será el estímulo a asumir un compromiso activo con acciones dirigidas a atacar las causas de las conductas criminales, pese a que dichas acciones posiblemente sean las únicas que permitan un tratamiento eficiente del problema a largo plazo. De este modo, la privatización de la seguridad puede estar contribuyendo a adormecer la sensibilidad sobre un problema social básico, así como la voluntad de actuar sobre él en aquellos que por su capacidad económica gozan de mayor poder e influencia, y de cuyo ejercicio regular de responsabilidad cívica la sociedad podría obtener los mayores réditos. No debe extrañar, por ende, que sea en los barrios de menores recursos, que no pueden privatizar su seguridad, donde surjan con mayor frecuencia iniciativas de apoyo mutuo para enfrentar la delincuencia, así como una preocupación compartida por erradicar sus causas. 
iii) Segmentación social. Los patrones de comportamiento que se van consolidando en un contexto de inseguridad frente al crimen y la violencia se reflejan en la estructura social y, en particular, en las relacio. nes entre estratos socioeconómicos distintos. El temor es propicio a la formación de estereotipos de los delincuentes que incorporan muchos rasgos de la pobre. za, la que comienza a percibirse como el germen de "clase:s peligrosas". Esto refuerza la tendencia de los sectores medios a tomar distancia de los pobres, a evitar sus barrios, sus áreas de esparcimiento, sus medios de transporte colectivo y los servicios públicos a los que acceden. De este modo, la inseguridad pública termina reforzando la segmentación social que, como veremos más adelante, es uno de los fenómenos que le da origen.

En suma, tanto el crimen como las respuestas ante el crimen son parte importante de las causas y de los efectos del deterioro del capital social de las comunidades. El capital social se acumula en redes de reciprocidad basadas en la confianza, que son las que hacen posible emprendimientos colectivos beneficiosos para la comunidad. Cuando el capital social falta o se debilita aumenta la inseguridad personal. Los guetos urbanos constituyen un ejemplo extremo de deterioro del capital social.

\section{L.a evolución de los delitos}

Ahora bien, ¿cuáles son los hechos que justifican esta serie de percepciones, comportamientos e iniciativas legales e institucionales en torno a la seguridad pública? Hay quienes sostienen que ta sociedad uruguaya experimenta un miedo al crimen innecesario e injustificado, posiblemente alimentado por la importancia que dan los medios de comunicación a las noticias truculentas o los materiales violentos, y que el crimen tiene en la televisión y en la prensa una prominencia mucho mayor que la que tiene en la vida de las personas. Para aclarar este punto es preciso recurrir a la información disponible sobre victimización y evolución de los delitos en los últimos años en el país.

La lectura de los resultados de una encuesta de opinión de junio de 1995 muestra que algo más de cuatro de cada diez uruguayos (el $42 \%$ ) conocía de primera mano la inseguridad pública, ya sea como víctimas de robo o de intento de robo en su casa (31\%) o fuera de su casa (21\%). Estos datos permiten concluir al analista que "Las preocupaciones por la seguridad pública, especialmente en Montevideo, están sólida. mente arraigadas en las experiencias personales y familjares de la ciudadanía” (González, 1995).
Las cifras sobre algunos delitos en Uruguay entre 1980 y 1994 también parecen apoyar esta conclusión. El aumento de la delincuencia en los últimos años se revela más en las rapiñas y los homicidios que en los hurtos (cuadro 5). Según el código penal uruguayo, a diferencia de los hurtos, en las rapiñas hay violencia, o amenaza de violencia, de modo que lo que indican los registros oficiales es un marcado aumento de la violencia en los hechos delictivos. Al respecto, se debe tener en cuenta que la probabilidad de registro aumenta con la violencia asociada a los delitos, mientras que la probabilidad de registro de hurtos menores disminuye a medida que la ciudadanía toma conciencia de que el tiempo invertido en la denuncia no es compensado con una razonable posibilidad de resarcirse de la pérdida."

CUADRO 5

Uruguay: Evolución de algunos delitos, por quinquenios, entre 1980 y 1995

(Promedies anuales)

\begin{tabular}{lrrrr}
\hline Delitos & $1980-1984$ & $1985-1989$ & $1990-1994$ & 1995 \\
\hline Rapinas & & & & \\
$\quad$ Montevideo & 1017 & 1698 & 2474 & 4174 \\
Interior & 94 & 195 & 291 & \\
Total del pais & 1101 & 1893 & 2765 & \\
Hurtos & & & & \\
$\quad$ Montevideo & 12862 & 27120 & 26170 & \\
Interior & 12947 & 19836 & 24342 & \\
Total del pais & 25809 & 46956 & 50512 & \\
& & & & \\
Homicidios & & & & \\
Montevideo & 52 & 67 & 91 \\
Interior & 87 & 90 & 111 \\
Total del país & 139 & 157 & 202 & \\
\hline & & &
\end{tabular}

Fuente: Elaboración propia basada en cifras del Ministerio del lnterior, República Oriental del Uruguay. Para 1995; El país, $1996 \mathrm{~b}$.

\footnotetext{
"Los especialistas en estadísticas sobre criminalidad han destacado el subregistro de algunos delitos derivado tanto de sesgos que afectan a las denuncias como de sesgos que afectan a los organismos de control de la delincuencia. Por ejemplo: si se debilita la conftanza en la eficiencia policial o judicial se reducirán las denuncias de ciertos delitos, especialmente los de menor gravedad. Al contrario, el aumento de los seguros contra robos incentiva las denuncias porque éstas se exigen como condición para resarcir los daños. Los delitos sexuales pueden ser reportados o no dependiendo de la fuerza de los estigmas sexuales y del grado de comprensión y simpatía que innestren policías, jueces y la opinión pública con la situación de las víctimas. Det lado de los organismos encargados del control de la delincuencia se destaca un fuerte sesgo hacia el registro de detitos cometidos por los segmentos sociales de menores recursos, así como el subregistro de los que cometen típicamente los sectores medios y altos (fraude, dolo, tráfico de influencias, corrupciơn, vandalismo de jóvenes de esos estratos). Vérase uts análisis detallado de los problemas metodológicos envueltos en la investigación sobre delincuencia en Hirschi y Selvin, 1967.
} 


\section{IV}

\section{Comportamientos delictivos, pobreza}

\section{y marginalidad}

No existen en el país estudios empíricos que permitan conectar las variaciones en distintos tipos de delitos con cambios en distintos aspectos de la situación de la población. La teoría más difundida y simple es que los delitos los cometen quienes encuentran dificultades para obtener por medios legítimos los objetos deseados. Esta idea dirige la atención hacia la estructura de oportunidades a la que tienen acceso distintos segmentos de la sociedad para alcanzar las metas culturalmente aceptadas. Una primera derivación es que, dadas sus mayores dificultades para obtener lo que desean por medios legítimos, los pobres cometerían más delitos que los no pobres. Si así fuera, la evolución de los delitos debería estar relacionada con la evolución de la pobreza. Esto no parece haber ocurrido en la historia uruguaya reciente. Por ejemplo, mientras los índices de pobreza urbana mostraron una tendencia declinante -de $22.3 \%$ a $12.8 \%$ - entre 1989 y 1994 (INE, 1996), no ocurrió lo mismo con distintos indicadores de delincuencia. Así, las rapiñas aumentaron de 1968 a 3189 , los hurtos se redujeron de 49045 a 47967 y los homicidios se elevaron de 198 a 222.

Una segunda derivación lleva a diferenciar den. tro de la pobreza un sector marginal - que encuentra fuertes impedimentos para integrarse a la sociedad a través de sus canales legítimos- y a vincularlo con la delincuencia. Antes de analizar la evidencia disponible en busca de algún tipo de aproximación a la puesta a prueba de dicha relación, conviene precisar el concepto de marginalidad que se maneja en este artículo y dada la historia del término en la región, referirse a las diferencias entre la "vieja" y la "nueva" marginalidad.

\section{Vieja y nueva marginalidad: características generales}

Un camino para destacar las peculiaridades de la marginalidad actual es distinguirla de la que caracterizó a la población que, a partir de los años cincuenta y en la mayoría de los países de la región, se desplazó masivamente del campo a las ciudades, asentándose de manera precaria en su periferia. Pese a su situación de pobreza, muchos migrantes experimentaron ese des- plazamiento como un ascenso social en al menos dos sentidos. Primero, por la excitación de la conquista de una ciudadanía urbana que, además de su contenido simbólico, significaba un acceso real a consumos mucho más variados que los disponibles en el campo, así como a servicios de salud y educación y a infraestructura de vivienda y esparcimiento que en el medio rural eran prácticamente inaccesibles; segundo, porque las transferencias masivas de población se dieron en un momento de expansión de mercados internos que, estimulados por la sustitución de importaciones, tuvieron en ese período capacidad de absorber mano de obra y de mantener abiertas importantes avenidas de movilidad social.

La marginalidad de los años noventa parece estar marcada por otras características. En primer lugar, se define más con respecto al mercado de trabajo y a ta estructura ocupacional que en relación a la localización geográfica de la vivienda, aun cuando se reconoce que los asentamientos precarios periféricos continúan representando su núcleo duro. En segundo lugar, la población de esos asentamientos es mayoritariamente de origen urbano, es decir, la memoria de un pasado rural pobre ya no constituye el marco para evaluar su situación de hoy. Los resultados de una investigación reciente sobre asentamientos precarios en Montevideo corroboran la anterior afirmación (Cecilio, 1995): ya en 1984 el $93.5 \%$ de los que residían en esos asentamientos habían nacido en áreas urbanas, y tres de cada cuatro en el mismo Montevideo. Más aún, si en los asentamientos marginales de los sesenta operaba un fuerte elemento de atracción de las ciudades, los de los noventa parecen estar marcados por procesos de expulsión de las ciudades. En 1995, cerca de seis de cada diez jefes de hogar montevideanos en asentamientos precarios declaraba que su vivienda anterior había sido casa o departamento (Cecilio, 1995, p. 103).

En tercer lugar, puede señalarse que si lo característico de los años sesenta era la ampliación de las vías de movilidad, lo que se destaca en los noventa es su estrechamiento. Caducan con rapidez los canales tradicionales y se abren con lentitud las avenidas alternativas. Este es uno de los efectos de la globalización de las economías, su mayor apertura y una recon- 
versión de la producción de bienes y servicios orientada a una mayor competitividad internacional. En búsqueda de más competitividad, las empresas reducen su personal, incorporan tecnología y modifican sus criterios de reclutamiento, planteando problemas de inestabilidad ocupacional a segmentos cada vez más amplios de la fuerza de trabajo. Cabe recordar que la falta de una comunidad ocupacional que oficie como grupo de referencia estable implica no contar con ese espacio en el mundo de la producción que, a lo largo de los siglos, fue una de las fuentes principales de formación de las identidades de los trabajadores.

Debido a que el país no ha exhibido fuertes crecimientos demográficos, ni rápidas y masivas migraciones dil canpo, ni las agudas diferenciaciones ruralurbanas y las discriminaciones étnicas que caracterizaron a otros países de la región, la integración de la sociedad urbana uruguaya no fue mayormente afectada por las modalidades de incorporación de los migrantes rurales que singularizaron a la vieja marginalidad. Esa situación convierte al país en un ámbito adecuado para observar las nuevas formas de marginalidad, cuyos rasgos no resultan ni superpuestos ni obscurecidos por los efectos de formas de marginalidad con causas y consecuencias distintas.

\section{Pobreza y pobreza marginal}

La marginalidad como posición social resulta del efecto combinado de tres elementos: las metas culturales, el accesc a los medios para alcanzar esas metas y las capacidades de los individuos que ocupan esa posición. ${ }^{\text {î. }}$

Las metas que la cultura legitima definen los estilos de vida a los que aspira la mayoría de la población. En sociedades con fronteras rígidas entre las clases, al igual que en comunidades locales fuertemente estrucluradas y relativamente aisladas, es posible la formación de subculturas cuyas metas se apartan de las que predominan en la sociedad. Este no es el caso de Uruguay. Por un lado, la ideología igualitaria, la homogereidad étnica de la población y la ausencia de

\footnotetext{
${ }^{12}$ Sin dıda, esta conceptualización simplifica burdamente la tiqueza de siznificados de la nocion de marginalidad. A fines de la década de 1960 hubo una extensa discusión del tema desde distintos enfoques -incluyendo la crítica al capitalismo desde una perspectiva mat xista - en la que participaron Roger Vekemans, José Nun, Fernando Henrique Cardoso, Antbal Quijano, Gino Germani y otros. Véase ui buen resumen de dicha polémica en un número totalmente dedicido al tema de la marginalidad en la Revista latinoumericana de snctiología. 1969, vol. V, $\mathrm{N}^{\circ} 2$.
}

componentes "feudales" en su historia, impidió la creación de barreras rígidas de clase. Por otro, la rápida expansión reciente de los medios de comunicación ha terminado de disolver las ya débiles fronteras de las comunidades locales. Por lo tanto, se puede afirmar que no existen barreras culturales que puedan justificar que haya segmentos de la población aislados de los estilos de vida predominantes.

La disponibilidad de medios para alcanzar las metas culturales depende fundamentalmente de la capacidad de la economía para absorber mano de obra en empleos productivos, lo que en última instancia responde a una combinación de estilo de desarrollo y ritmo de crecimiento. Dentro de ese marco general, sin embargo, para cada etapa del ciclo de vida de las personas la estructura de oportunidades se va definiendo por el acceso a instituciones que en su conjunto posibilitan una formación que responde a los requerimientos del mercado de trabajo, siendo el sistema educativo el canal principal de movilidad social.

Los pobres marginales se distinguen del resto de los pobres por su menor capacidad para hacer uso de la estructura de oportunidades existente, ya sea organizándose para satisfacer las demandas de bienes y servicios de la población, utilizando las vías de acceso a los servicios públicos y al crédito o maximizando el aprovechamiento de las ofertas del sistema educativo y las oportunidades del mercado laboral. ${ }^{3}$ Su estito de vida revela la ausencia de un proyecto de incorporación a la sociedad global. Sus actitudes y comportamientos reflejan una baja autoestima y la falta de expectativas respecto a la posibilidad de modificar de manera significativa, a través del propio esfuerzo, su bajo nivel de bienestar. ${ }^{14}$

Las capacidades de cada individuo resultan de una combinación de sus activos biológicos (discapacidades, estado de salud); de conocimiento (nivel y calidad de la educación recibida, experiencia profesional); sociales (contactos y posibilidades de movilizar voluntades ajenas en beneficio propio); materiales (capital fijo y

\footnotetext{
${ }^{13}$ En una perspectiva parecida, Irarrázabal ( I995) coordinó en Chile un estudio que distingue entre pobres habilitados y no habilitados. Para diferenciarlos se consideraron indicadores de éxito socioeconomico relativo entre familias que compatian similares restricciones económicas. Las fanilias pobres habilitadas eran aquellas que respondían positivamente a una serie de indicadores de esfuerzos por surgir.

${ }^{14}$ La autoestima individual suele ser una consecuencia del signo (positivo o negativo) y del nivel de estructuración de los mensajes que, en respuesta a sus acciones, el individuo va recibjendo a lo largo de su vida de las personas significativas de su entomo.
} 
móvil); culturales (creencias, ética de trabajo, etc.), y motivacionales (logro, autoestima). Cada uno de estos activos se forma y madura a edades específicas y, por ende, tiene distinta relevancia en diferentes momentos del ciclo de vida individual. Así, el principal activo de niños y adolescentes son sus familias, puesto que a través de ellas van nutriendo y consolidando sus otros activos.

\section{V}

\section{Marginalidad y familia}

\section{Familia y formación de capacidades en los niños}

Las formas de constitución y composición de las familias son predictores importantes de cómo les va a los niños en las escuelas, donde los que viven con uno solo de sus padres o con los padres en unión consensual muestran tasas de rezago escolar significativamente superiores al resto. ${ }^{15}$ Una serie de estudios realizados en Uruguay revelan los efectos de la familia sobre otros aspectos de la niñez y la adolescencia. Por ejemplo, los niños concebidos fuera del matrimonio (ilegitimidad de nacimiento) muestran una tasa de mortalidad infantil mucho mayor que el resto, y los que no conviven con ambos padres biológicos exhiben mayores daños en distintas dimensiones del desarrollo psicomotriz (CEPAL, 1991; Universidad de la República, Facultad de Medicina, Departamento de Psicología Médica, 1996).

La constitución y composición del hogar también ha probado ser un buen predictor de comportamientos delictivos. Por ejemplo, se ha encontrado que más del $70 \%$ de todos los jóvenes en centros de detención juvenil en Estados Unidos provienen de hogares con padre ausente (Dafoe Whitehead, 1993, p. 77).

\footnotetext{
${ }^{15}$ Esta afirmación es corroborada por resultados de múltiples estudios. Respecto a Unguay, véase Filgueira (1996) y también cEpal (1987 y 1990b). En Estados Unidos, la Secretaría de Salud y Servicios Humanos realizó una amplísima investigación del tema en más de 60000 niños. J. Wilson resume sus conclusiones con las siguientes palabras: "En todos los niveles de ingreso, salvo el muy alto (más de 50000 dólares al aío), en el caso de los dos sexos y para los blancos, negros e hispanos por igual, los niños que vivian con una madre divorciada o que nunca se había casado, estaban claramente peor que los pertenecientes a familias que vivian con los dos progenitores. En comparación con tos niños que vivian con sus dos padres biologicos, los niños de familia con un solo progenitor eran dos veces inás propensos a ser expulsados o suspendidos en ta escuela, a sufrir problemas emocionales o de la conducta y a tener dificultades con sus compañeros. También eran mucho más proclives a tener una conducta antisocial" (Wilson, 1994).
}

\section{La familia de los menores internados en el Ins- tituto Nacional del Menor}

Para investigar esa relación en Uruguay se examinaron datos provenientes del Sistema de Información de la Infancia del INAME, cuyo archivo constituye una fuente de enorme riqueza para conocer en su génesis los factores determinantes más inmediatos de las conductas antisociales. Los datos correspondían a 2133 niños y adolescentes de uno y otro sexo cuyas causales de ingreso (inconducta social e infracciones) se podían interpretar como comportamientos alejados de los patrones aceptados y que evidenciaban un daño serio en sus vínculos con la sociedad, ${ }^{16}$ La mayoría $(81.5 \%)$ de estos niños y adolescentes se encontraban internados en el INAME o en hogares sustitutos. El análisis abarca el período 1990-1995.

Existe amplia evidencia de que las familias intactas tienen una capacidad de socialización mayor que aquéllas en que falta uno de los padres biológicos. El estudio mencionado de Filgueira corrobora que dicha capacidad se debilita en ausencia de uno de los padres biológicos, aun en los casos en que otra persona esté cumpliendo ese rol. De modo que si la marginalidad, como la hemos definido, es principalmente un problema de capacidades para hacer uso de la estructura de oportunidades existentes en una sociedad, y si los activos que forman esas capacidades en niños y adolescentes son provistos fundamentalmente por las familias, es razonable suponer que los niños criados en familias no intactas tengan una propensión a la margi-

\footnotetext{
${ }^{16}$ Los ingresos por inconducta social se desagregan según las causales siguientes: mendicidad, vagancia, abandono del hogar, consumo de drogas, prostitución y vandalistno; el $84 \%$ de los casos se concentra en vagancia y abandono del hogar. Los ingresos por infracciones comprenden: hurto, rapiña, lesiones, homicidios, tráfico de drogas, violación y tentativa de hurto; alrededor del $70 \%$ de los casos corresponden a hutos y rupinas.
} 
nalidad mayor que aquellos que provienen de familias intactas, máxime en sectores de escasos recursos. ${ }^{17}$

be los menores analizados, sólo uno de cada tres (31.2\%) convivía en una familia intacta (con ambos padres biológicos) en el momento de su internación, resultado similar al citado con referencia a centros de detención juvenil en Estados Unidos. De los niños que en el momento de su internación no convivían con ambos padres biológicos, el $63.8 \%$ residía con su madre, un $30.8 \%$ con un padrastro o una madrastra y el $5.4 \%$ restante sin sus padres.

Aunque este resultado podría apuntar a que los menores que no cuentan con una familia intacta tienen una mayor probabilidad de cometer infracciones o inconductas sociales, no hay pruebas suficientes para afirmar que existe una relación causal entre estas dos variables. Ambas podrían estar determinadas por una tercera, por ejemplo, la pobreza. La información que propolcionan los registros del iNAME no permite distinguir entre los efectos de la estructura familiar y los efectos de la pobreza, al no incorporar datos sobre caract:rísticas del hogar de los internados que habiliten la comparación con las de hogares pobres. Tampoco la Encuesta Continua de Hogares permite comparar tol perfil familiar de los menores en hogares pobres con el de los menores del JNAME, dado que no discrimina a los padres por su relación biológica con las personas que en el hogar figuran como hijos del jefe de familia.

Para intentar aislar el efecto de la constitución far miliar de los efectos de las situaciones de pobreza sobre la marginalidad de los menores, se reexaminaron los dalos de un estudio realizado por la Oficina de la CEPAL tn Montevideo sobre características de las familias en una muestra de niños en escuelas públicas. Las situaciones de esos niños se han comparado con las de los menores analizados en el JNAME (cuadro 6). Los resultados muestran que, independientemente de la gravedad de las carencias económicas del hogar, el perfil familiar de los menores del INAME es totalmente distinto al de los demás niños. En efecto, entre estos

\footnotetext{
${ }^{17} \mathrm{La}$ pre sencia del padre es clave para proveer o reforzar ciertos activos de los nijios: i) como modelo forjador de identidades, especiatmenti: para tos varones; ii) como agente de contención, de creación de tábitos de disciplina y transmisor de experiencias de vida; iii) comc soporte material, ya que la falta del aporte del padre reduce corsiderablemente los ingtesos del hogar, particularmente porque lis mujeres ganan entre un $20 \%$ y un $50 \%$ menos que los hombres, $y$ iv) como capital social, en la medida en que la ausencia del padre implica la pérdida de una línea de contacto con las redes masculinis, tanto en el mundo del trabajo como en el de la política y que ad:zmás, al cortarse el nexo con las redes de parientes que podría aportar el padre, dismímuen significativamente los vínculos familiare: potenciales.
}

últimos, el $67.3 \%$ de los que se hallan en situación de indigencia, el $79.4 \%$ de los pobres no indigentes y el $83.9 \%$ de los no pobres, convive con ambos padres biologicos, lo que contrasta fuertemente con la situación de los menores del INAME. La característica singular más importante de estos menores es la ausencia del padre. Sobre esta base, y pese a que el promedio de edad de los menores del INAME estudiados era de alrededor de 15 años (contra 10 y 11 años de los niños de escuelas públicas analizados), es razonable concluir que esos menores provienen de hogares con características familiares significativamente diferentes de las de los hogares pobres e indigentes uruguayos. Más bien, tanto esta información como el juicio de personas con un conocimiento amplio del funcionamiento del INAME apuntan a un perfil de hogares en situación de pobreza marginal, una de cuyas características más importantes es la familia incompleta e inestable.

El hecho de que los padres no estén casados en el momento del parto define formalmente el nacimiento como ilegítimo. Tal situación, que afecta al $45 \%$ de los menores del INAME estudiados, aumenta el riesgo de ausencia del padre en el grupo de convivencia (cuadro 7 ). ${ }^{\text {Is }}$

La rápida elevación de las calificaciones exigidas a los jóvenes para incorporarlos al sector moderno de la economía no hace más que acentuar el efecto marginalizador de las familias incompletas e inestables, haciendo más evidente la desventaja de no contar con el apoyo de una familia intacta. En efecto, extender la formación implica prolongar las actividades de apoyo material, emocional, intelectual y de formación de hábitos y disciplinas de trabajo para las cuales las familias son insustituibles. Los niños y jóvenes de las familias que por ser inestables o incompletas no disponen de esos activos estarán en peor condición que otros para hacer uso de las oportunidades existentes.

\section{Familias con padre ausente}

Las características de los hogares de Ios menores del INAME brindan pistas muy importantes sobre algunos rasgos de la nueva marginalidad y dirigen la atención hacia los cambios en las familias. Si efectivamente hay una tendencia en la sociedad uruguaya a una mayor inestabilidad y quiebre de las parejas, y a un aumento de la ilegitimidad de nacimiento y de los niños que no conviven con ambos padres biológicos, de no mediar

\footnotetext{
Ix Charles Murray (1993) sugiere considerar la ilegitimidad como uno de los signos más importantes de marginalidad y desintegración social.
} 
CUADRO 6

Uruguay: Características del grupo familiar de escolares de cuarto grado y de menores del Instituto Nacional del Menor (INAME)

\begin{tabular}{lccccc}
\hline & \multicolumn{3}{c}{ De los escolares" } & & \multicolumn{2}{c}{ De los menores del JNAME" } \\
\cline { 2 - 5 } Grupo fatniliar & Indigentes & Pobres no indigentes & No pobres & & Total \\
\hline Madre sola & 7.1 & 5.2 & 6.5 & 43.9 \\
Padrastro o madrastra & 4.4 & 3.4 & 3.2 & 21.2 \\
Ambos padres biológicos & 67.3 & 79.4 & 83.9 & 31.2 \\
Otros & 9.7 & 10.3 & 4.1 & 3.7 \\
\hline
\end{tabular}

Fuente: Para los escolares, Encuesta para un Diagnóstico de la Educación Básica en Uruguay, Oficina de la CEPAL en Montevideo, 1990. Para los menores del SENAME, elaboración de datos tomados del archivo SIPI del INAME, 1990-1995.

a Estudiantes de cuarto grado de escuelas públicus de Montevideo y Tactarembo.

h Menores internados en el INAME por infracciones o inconducta social.

CUADRO 7

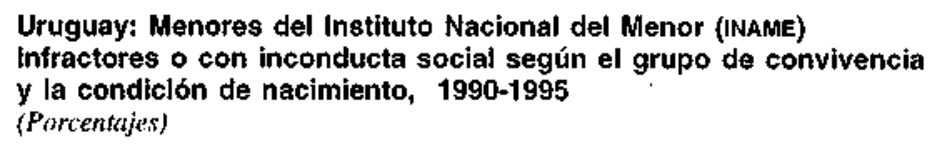

\begin{tabular}{|c|c|c|c|c|c|c|}
\hline \multirow{3}{*}{$\begin{array}{l}\text { Presencia de los padres } \\
\text { en el grupo de convivencia }\end{array}$} & \multicolumn{6}{|c|}{ Condición de nacimiento } \\
\hline & \multicolumn{3}{|c|}{ Sobre el total de menores investigados } & \multicolumn{3}{|c|}{ Sobre el total de menores en cata categorá } \\
\hline & Legítimo & Ilegítimo & Total & Legítimo & Ilegítimo & Totil \\
\hline Sólo madre & 20.9 & 23.0 & 43.9 & 38.1 & 51.0 & 43.9 \\
\hline Madre y padre & 21.2 & 10.0 & 31.2 & 38.4 & 22.5 & 31.2 \\
\hline Padrastro o madrastra & 10.0 & 11.2 & 21.2 & 18.3 & 24.8 & 21.2 \\
\hline Otros & 2.9 & 0.8 & 3.7 & 5.2 & 1.7 & 3.7 \\
\hline Total & 55.0 & 45,0 & $\begin{array}{c}5000 \\
(2133)\end{array}$ & $\begin{array}{c}100,0 \\
(1 \quad 172)\end{array}$ & $\begin{array}{l}100.0 \\
(961)\end{array}$ & $\begin{array}{c}1000 \\
(2133)\end{array}$ \\
\hline
\end{tabular}

Fuente: Elaboración propia, sobre la base del archivo SIPI del INAME.

sustanciales mejoras en la situación socioeconómica general de los estratos bajos urbanos, es dable anticipar una incidencia creciente de comportamientos marginales.

Al pasar revista a las tendencias recientes de la ilegitimidad de nacimiento (cuadro 8), vemos que en 1975 uno de cada cinco niños nacía fuera del matrimonio, y que en 1993 esa proporción era de uno cada tres. Este proceso se aceleró en la última década, puesto que en el período 1975-1984 la ilegitimidad creció un $14 \%$, y un $50 \%$ aproximadamente entre 1984 y 1993. El incremento de las tasas se verifica en todos los grupos de edad.

Si, como parecen sugerir los antecedentes de los menores internados en el INAME, la ilegitimidad de nacimiento se asocia a estructuras familiares que favorecen el surgimiento de problemas de conducta e infracciones a la ley, son preocupantes las consecuen-
CUADRO 8

Uruguay: Ilegitimidad de nacimientos

1. En Montevideo, 1975, 1984 y 1993

$\begin{array}{lc}\text { Años } & \text { Tasas de ilegitimidad (\%) } \\ 1975 & 20.9 \\ 1984 & 23.8 \\ 1993 & 34.5\end{array}$

2. En el pais, 1961 y 1988

Edad de las madres

\begin{tabular}{cc}
- & \multicolumn{2}{c}{ Tasas de ilegitimidad (\%) } \\
\cline { 2 - 2 } 1961 & 1988 \\
25.7 & 47.9 \\
15.5 & 30.5 \\
11.5 & 20.9 \\
11.7 & 21.2 \\
\hline
\end{tabular}

Fuente: Elaboración propia con datos del Boletín de Estudisticas Vitales del Instítuto Nacional de Estadística (INE) y además, para Montevideo, con datos de la División de Estadística del Ministerio de Salud Pública. 
cias sociales del importante aumento de nacimientos ilegítimos que se ha observado en la última década en Uruguay.

l'areciera evidente entonces que para conocer la evolusión de los problemas vinculados a la marginalidad e: preciso seguir muy de cerca las estadísticas sobre cámbios en la composición y constitución de las familias. Sin embargo, las fuentes estadísticas oficiales sólo muestran una parte ínfima de los cambios más importantes que experimentan las familias; el resto -especialmente los núcleos familiares dentro de los hogares y las familias reconstituidas o reensambladas- queda oculto al análisis. Aun así, esa punta visible ts suficiente como para señalar que la ilegitimidad está creciendo, y también la proporción de uniones consensuales o concubinatos dentro del total de hogaris, particularmente entre los hogares jovenes (cuadro 9). Con respecto a la jefatura femenina de núclers familiares, su detección se dificulta por la tendencia de muchas madres en esa condición a buscar refugits en su hogar de origen.

Ante el panorama que se desprende de las tendencias recién mencionadas, los responsables de la política social uruguaya deberían encontrar respuesta rápida a lia pregunta siguiente: ¿cuáles son las condiciones que favorecen el aumento de la tasa de ilegitimidad, da las uniones consensuales y de los núcleos familiarts con padres ausentes? Ciertamente, no es fácil ponderar el peso relativo de cada una de las muchas condiciones que contribuyen al aumento de estos fenómenos. Pero hay al menos un par de factores cuya consideración no puede obviarse al explicar las trans. formaciones en los modos de constituir familias. Ellos son los cambios culturales relativos a la sexualidad y la rentencia de los varones jóvenes a asumir respon- sabilidades de largo plazo en el mantenimiento de una familia.

\section{a) Cambios en la sexualidad}

Se asiste a una rápida flexibilización de los patrones normativos que regulan el comportamiento sexual. Entre las causas del fenómeno se hallan la amplia difusión de técnicas de control de la natalidad y el consiguiente aumento de la posibilidad de diso. ciar la reproducción de la sexualidad; la expansión de la participación de la mujer en el mercado de trabajo y su consecuente mayor independencia económica $y$, por último, el deterioro de las instituciones primarias como la familia y la comunidad local y el consecuente debilitamiento de su capacidad para controlar y sancionar comportamientos.

Esta combinación de factores contribuyó sin duda al marcado descenso que se observa en las edades de iniciación sexual, así como al aumento de embarazos adolescentes. Este último sorprende, ya que los logros educativos cada vez mayores de la mujer y la disponibilidad creciente de información sobre el control de la natalidad generaban expectativas de signo opuesto.

Una buena parte de los embarazos precoces, considerando como tales a los que se producen antes de los 20 años, son eslabones importantes en la cadena de procesos que conducen a la marginalidad. Las tasas de ilegitimidad entre estas madres son mayores que en los restantes grupos de edad y han crecido continua y aceleradamente en los últimos treinta años en el país (cuadro 10 ). El aumento de la tasa general de ilegitimidad se explica parcialmente por un aumento paralelo de la proporción de nacimientos de madres adolescentes sobre el total de nacimientos (véase la última línea del cuadro).

CUADRO 9

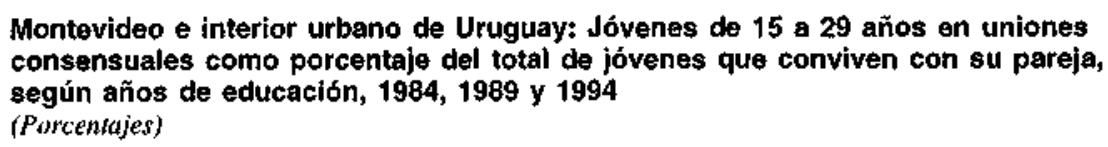

Montevideo e interior urbano de Uruguay: Jóvenes de 15 a 29 años en uniones consensuales como porcentaje del total de jóvenes que conviven con su pareja, según años de educación, 1984, 1989 y 1994 (Porcentajes)

\begin{tabular}{llcrr}
\hline Años & Años de educación & Montevideo & Interior urbano & Total ubano \\
\hline 1984 & Nueve y menos & 17.9 & 16.1 & 17.0 \\
& Diez y más & 4.8 & 4.5 & 4.6 \\
& Total & 12.6 & 12.7 & 12.7 \\
1989 & & 22.6 & 23.5 & 23.0 \\
& Nueve y menos & 6.1 & 7.2 & 6.5 \\
& Diez y más & 14.6 & 18.5 & 16.7 \\
1994 & Total & 30.8 & 30.0 & 30.4 \\
& Nueve y menos & 14.8 & 13.2 & 14.2 \\
& Diez y más & 22.7 & 24.3 & 23.6 \\
\hline
\end{tabular}

Fuente: Elaboración propia, con datos de la Encuesta Continua de Hogares, del JME. 
CUADRO IO

Uruguay: Evolución de las tasas de ilegitimidad de los nacimientos, según la edad de la madre

\begin{tabular}{llllllll}
\hline Edad de la madre & 1961 & 1966 & 1971 & 1976 & 1981 & 1985 & 1993 \\
\hline (1) Hasta 19 af̂́s & 26.5 & 23.4 & 30.3 & 31.1 & 41.7 & 45.4 & 63.2 \\
(2) Total & 18.1 & 19.1 & 21.7 & 22.6 & 25.3 & 26.5 & 34.5 \\
Relación (1)/(2) & 1.44 & 1.23 & 1.40 & 1.38 & 1.65 & 1.71 & 1.83 \\
\hline
\end{tabular}

Fuente: Elaboración propia, con datos de las estadísticas vitales del INE; para 1993, datos de Ja División de Estadística del Ministerio de Salud Pública del Uruguay correspondientes a Montevideo, que suelen ser $10 \%$ inferiores a tas tasas nacionales.

La asociación de la maternidad adolescente y la marginalidad no se agota en la ilegitimidad de los nacimientos. Un estudio reciente del Instituto Nacional de la Mujer y la Familia arroja los siguientes resultados:

i) Las parejas de las madres precoces son más inestables que las de las madres no precoces, lo que se refleja en un mayor porcentaje de uniones consensuales y de divorciadas y separadas. Estas conclusiones corroboran los hallazgos de otros estudios realizatos en el país y citados por la autora. 19

ii) La mayoría de las madres precoces desertan del sistema educativo. Con ello no sólo debilitan sus poijbilidades de realización personal al disminuir sus sportunidades de empleo y ajslarse de los importantes ímbitos de socialización que constituyen los centros te enseñanza, sino que cohíben el desarrollo de uno de los activos más importantes que pueden transferir a sus hijos.

iii) Las razones de este comportamiento que surgen de los estudios sobre madres adolescentes son yariadas. En general predomina la imagen de que las adolescentes pobres encuentran en su entorno social una respuesta positiva ante la maternidad. Pareciera que, a diferencia de los varones, fuera de la materniclad estas mujeres enfrentan un vacío en cuanto a roles alternativos que signifiquen un grado mínimo de reconocimiento social. En ese marco de desesperanza scerca de sus oportunidades de realización personal, el romanticismo y la avidez de afectos pueden interpretarse como formas de enriquecer la significación de sus vidas.

\footnotetext{
19 Urugutay, Ministerio de Educación y Cultura, Instituto Nacional du la Familia y la Mujer, 1995; esta investigación fue dirigida por María Elena Laurnaga. Los estudjos citados que corroboran tos hiallazgos se hatlan en Instituto Nacional de Alimentacion (INDA), 1989.
}

b) Algunas causas de la renuencia de los varones jovenes a constituir nuevos hogares

El segundo factor importante vinculado al crecimiento de la ílegitimidad y de los concubinatos entre los jóvenes de estratos pobres es la renuencia de los varones a asumir la responsabilidad principal por el mantenimiento económico de una familia. ${ }^{20}$ Tal renuencia es congruente tanto con la asociación positiva entre las tendencias de la nupcialidad y del salario real como con estudios que muestran una mayor propensión de los varones a contraer matrimonio cuanto mayor es el ingreso (Filgueira, 1996). Desde el punto de vista de las posibilidades de realización individual, el debilitamiento de la propensión a contraer matrimonio de los varones puede tener entonces una base de racionalidad económica que es conveniente considerar.

En efecto, de conformidad con datos de la Encuesta Continua de Hogares de Montevideo para el año 1994, alrededor de uno de cada tres $(34.5 \%)$ jóvenes varones de 20 a 30 años que trabajaban más de 20 horas por semana, estaba en condiciones de mantener una familia mínima - constituida por esposa e hijo pequeño- fuera de la pobreza (cuadro 11). Ello quiere decir que con su trabajo generaban ingresos equivalentes a dos veces y media la línea de pobreza de ese año.

Cuando se desagregan esos datos por nivel de instrucción se observa lo siguiente. Entre aquellos que habían completado el ciclo básico (nueve años de educación formal) menos de uno de cada tres $(30.2 \%)$ alcanzaba los ingresos mencionados. La situación no variaba demasiado con el bachillerato completo (35.2\%). Sólo en el $5 \%$ de los jóvenes que alcanzaban

\footnotetext{
20) Tal responsabilidad es particularmente importante para los jóvenes pobres, que en los estudios de opinión póblica se muestran mucho más de acuerdo que otros jovenes con la imagen tradicional de la división del trabajo por sexo según la cual los hombres participan en el mercado de trabajo y las mujeres se hacen cargo de las tareas domesticas.
} 
CUADRO II

Montevideo: Capacidad de sostener a la familia entre los ocupados con ingresos iguales o mayores a 2.5 líneas de pobreza que tienen de 20 a 29 años de edad y trabajan más de $\mathbf{2 0}$ horas semanales, 1994 (Porcentajes)

\begin{tabular}{|c|c|c|c|c|}
\hline \multirow{3}{*}{$\begin{array}{l}\text { Años de educación } \\
\text { aprobiddos } \\
\text { Hasta } 5 \text { años }\end{array}$} & \multicolumn{4}{|c|}{ Capacidad de sostener a la familia } \\
\hline & \multirow{2}{*}{$\frac{\text { No tiene }}{77.4}$} & \multirow{2}{*}{$\frac{\text { Tiene }}{22.6}$} & \multicolumn{2}{|l|}{ Total } \\
\hline & & & 100 & (53) \\
\hline 6 años & 78.7 & 21.3 & 100 & $(300)$ \\
\hline 7 añıs & 78.3 & 21.7 & 100 & $(115)$ \\
\hline 8 athis & 77.0 & 23.0 & 100 & (243) \\
\hline 9 aีkis & 69.8 & 30.2 & 100 & (334) \\
\hline 10 añ'ss & 64.6 & 35.4 & 100 & $(582)$ \\
\hline II años & 62.1 & 37.9 & 100 & $(322)$ \\
\hline 12 มกับS & 64.6 & 35.4 & 100 & (82) \\
\hline 13 aถ⿱艹)S & 62.7 & 37.3 & 100 & $(\mathrm{~J} 02)$ \\
\hline 14 abins & 58.1 & 41.9 & 100 & (148) \\
\hline 15 añus & 53.9 & 46.1 & 100 & (154) \\
\hline 16 aก๊̃s & 55.1 & 44.9 & 100 & $(127)$ \\
\hline 17 anios y ıás & 30.2 & 69.8 & 100 & (116) \\
\hline Tofal & 65.5 & 34.5 & $100(2$ & 26781 \\
\hline
\end{tabular}

Fuenta: Elaboración propia, con datos de la Encuesta Continua de Hogares de Montevideo, del INE.

17 anios de educación formal se podría encontrar una mayoría que generaba ingresos equivalentes a dos veces: y media la línea de pobreza. O sea, que para la maycría de los jóvenes ocupados que tenían menos de 17 atios de estudio, establecer una familia implicaba, a menos de disponer de un ingreso adicional, caer en la pobreza. ${ }^{21}$

Este diagnóstico se ve corroborado por la rejación entre las etapas del ciclo de vida familiar y la probabilidad de caer en la pobreza (cuadro 12). En la primera línea del cuadro se registran los hogares con jefes menores de 30 años en los que convive sólo la parej a y que representan sólo el $1.6 \%$ de los hogares de Montevideo. Como primera observación, la propor*

${ }^{21} \mathrm{La}$ interpretación de la renuencia de los varones jovenes con bajos nivelts educativos a constituir familia bajo las actuales condiciones del mercado de trabajo, debe hacerse en el marco de la importancia que se asigna en los estratos bajos a la división tradicional del trabajo yor sexo, según la cual el varón sería el único proveedor al manttnimiento económico del hogar. En efecto, preguntados por su aceptición o rechazo a la siguiente frase "La mujer tiene la responsabilifad de ocuparse de los hijos y la casa y el hombre de llevar dinero al hogar" el porcentaje de acuerdos se distribuyó de la sjguiente manera según el nivel de educación de los respondentes: Primoria incompleta, 63\%; Hasta 3er. año de secundaria, 61\%: Hasto 6o. aiio de secundaria, 22\%; Universitaria, $9 \%$. Véase El observa* dor, 1995. ción de parejas jóvenes sin hijos en el total de hogares es muy baja, to que indica que el inicio de la convivencia está fuertemente asociado con el nacimiento del primer hijo. La segunda observación es que prácticamente no hay pobres entre ellas.

La categoría siguiente, en cambio, incorpora casi un $11 \%$ de hogares formados por la pareja y al menos un hijo entre 0 y 4 años. Se puede apreciar que aproximadamente 30 de cada 100 de estos hogares caen en la pobreza, lo que más que duplica el índice de pobreza de Montevideo en ese año (12.4\%). A medida que se pasa a las etapas siguientes del ciclo de vida de las familias, aumenta la probabilidad de que los hijos aporten al ingreso del hogar y que otras instituciones compartan con los padres su cuidado y socialización. Con más tiempo libre, también aumenta la probabilidad de que el cónyuge complemente los ingresos del jefe de hogar. Como resultado, se reduce sustancialmente la incidencia de la pobreza. Los datos del cuadro muestran que los cambios en la situación económica del hogar a través de los ciclos de vida tamiliar también se confirman en los hogares no nucleares (extendidos y compuestos).

Para examinar la incidencia de la pobreza según el nivel de educación de los jefes de hogar, se consideraron sólo las etapas del ciclo de vida familiar de los hogares nucleares (cuadro 13). Se distinguieron dos grupos: los jefes de hogar que como tnáximo alcanzaron a completar el ciclo básico y aquellos que superaron el ciclo básico.

La incertidumbre con respecto a la capacidad de generar ingresos bloquea la formación de proyectos de familia, y la ausencia de tales proyectos desalienta los compromisos a largo plazo. Los varones jóvenes, especialmente los que sólo alcanzaron a completar el ciclo básico, sólo necesitan mirar a su alrededor para darse cuenta que al decidir liderar un nuevo hogar enfrentan un alto riesgo de permanecer o caer en la pobreza. Alimentada por la experiencia de su entorno inmediato, esa expectativa abona a su vez la renuencia a asumir el compromiso de constituir una familia. De ese modo, la debilidad estructuralmente condicionada del origen de las familias de estratos bajos afecta las probabilidades de que las nuevas generaciones cuenten con el apoyo material, emocional y normativo que pueden brindar las familias intactas.

Ciertamente, la racionalidad económica no es el único motivo de la renuencia de los varones jóvenes de estratos bajos urbanos a asumir responsabilidades familiares. Otro es la pérdida de contenido del pape] de jefe de hogar vinculado al debilitamiento de su po- 
Montevideo: Situación de pobreza según la etapa del ciclo de vida de la familia, 1994

\begin{tabular}{|c|c|c|}
\hline Etapa del ciclo de vida familiar & $\begin{array}{c}\text { Familias pobres } \\
(\%)\end{array}$ & $\begin{array}{l}\text { Composición del total } \\
\text { de las familias }(\%)\end{array}$ \\
\hline \multicolumn{3}{|l|}{ Familias nucleares } \\
\hline Sin hijos, jefes de 15-29 años & 0.7 & I.6 \\
\hline Con hijos de 0.4 años & 30.6 & 10.7 \\
\hline Con hijos de $5-14$ años & 20.8 & 15.7 \\
\hline Con hijos de $15-24$ alios & 6.1 & 12. \\
\hline Otras & 4.1 & $\mathrm{~J} 3.8$ \\
\hline Con jefe de 65 años y mús & 4.3 & 8.9 \\
\hline \multicolumn{3}{|l|}{ Familias no nucleares } \\
\hline Sin hijos, con menores & 38.3 & 1.- \\
\hline Sin bijos, sin menores & 4.9 & 7.2 \\
\hline Con hijos $0-4$ antos & 35.7 & 1.6 \\
\hline Con hijos 5.14 años & 28.0 & 3.3 \\
\hline Con hijos $>15$, con menores de $0-4$ años & 31.0 & 2.3 \\
\hline Con hijos $>15$, con menores de $5-14$ ainos & 22.6 & 1.9 \\
\hline Don hijos $>15$, sin menores & 7.7 & 4.1 \\
\hline Dtras familias no nucleares (unipersonales) & 2.5 & 15.7 \\
\hline Fotul & 12.4 & 100.0 (9 447 familias) \\
\hline
\end{tabular}

Fuente: Elaboración propia, con datos de la Encuesta de Hogares del INE.

CUADRO 13

Montevideo: Incidencia de la pobreza en hogares nucleares, por etapa del ciclo de vida familiar y según el nivel educativo del jefe de hogar, 1994

(Porcentajes)

\begin{tabular}{|c|c|c|c|}
\hline \multirow[b]{2}{*}{ Etapa del ciclo de vida familiar } & \multicolumn{3}{|c|}{ Nivel educativo del jefe de hogar } \\
\hline & Hasta 9 años & 10 años y unás & Totnl \\
\hline Hijos de 0 a 4 años & 51.4 & 8.9 & 30.6 \\
\hline Hijos de 5 a 14 años & 31.4 & 5.5 & 20.8 \\
\hline Hijos de 15 a 24 antos & 9.7 & 1,0 & 6.1 \\
\hline \multicolumn{4}{|l|}{ Sin hijos menores de 25 años } \\
\hline y con jefe menor de 65 años & 6.1 & 0.6 & 4.3 \\
\hline \multicolumn{4}{|l|}{ Sin hijos menores de 25 años } \\
\hline$y$ con jefe mayor de 65 años & 5.1 & - & 4.1 \\
\hline Total de hogares & 17.2 & 3.1 & 12,4 \\
\hline
\end{tabular}

Iuente: Elaboración propia, basada en datos de la Encuesta Continuta de Hogares de Montevideo, del INE.

cler dentro de la familia; de sus funciones de representación en la esfera pública, de su capacidad de transraitir habilidades útiles para el desempeño de los hijos en el mercado de trabajo y, fundamentalmente, de su función de proveedor principal o único del sustento del hogar. ${ }^{22}$

\section{VI}

\section{Procesos de segmentación social}

Para terminar se destacan algunos procesos de segmentación que contribuyen al aumento de la marginalidad en la sociedad uruguaya. La fuente principal de margi-
${ }^{22}$ En otro estudio se ha intentado describir la pérdida de contenido del papel del jefe de hogar a los ojos de los jóvenes varones de estratos bajos urbanos (Kaztman, 1992). 
nalidad es la escasez de oportunidades de empleos productivos, relativamente estables, que incorporen conocimiento científico y técnico, que cubran distintas prestaciones de la seguridad laboral y que generen ingresos como para mantener una familia de tamaño medio dent ro de estándares de dignidad socialmente aceptados. Este tema ha sido extensamente tratado en las publicaciones especializadas latinoamericanas bajo términos como "heterogeneidad estructural" o "marginalidal" y más recientemente "exclusión", y constituye el telón de fondo del análisis que sigue.,3.3

En esta sección se examinará la segmentación como un proceso de formación de fronteras sociales y disminución de las oportunidades de interacción entre personas de origen socioeconómico distinto. Su prin cipal consecuencia es el debilitamiento de la integración de la sociedad y sus mecanismos centrales son la segrıgación residencial y la educativa.

\section{Segregación residencial}

El conjunto de los asentamientos precarios puede ser vistc como uno de los polos de un proceso de segregación residencial. Se ha estimado que la cantidad de viviendas en los asentamientos precarios en Montevideo jasó de 2541 en 1984 a 4835 en 1990 y a 7013 en 1 1994 , es decir, se triplicó en diez años y su incremenio se aceleró a partir de 1990 (Cecilio, 1995). Entre 1984. y 1994 no se registraron variaciones significativas en la estructura de edad de sus poblaciones (cuadro 4). La presencia de niños es mucho mayor que a nivel de Uruguay: según el censo de 1985 los menores de 10 años representaban el $17.1 \%$ de la población de Montevideo, mientras que un año antes la cifra para los asentamientos precarios era de $33.5 \%$.

Tal como ha sido denunciado en los últimos meses en diarios y revistas, algunos asentamientos precarics en Montevideo se están convirtiendo en guetos. ${ }^{24}$

\footnotetext{
${ }^{23}$ Vésise un extenso examen del terna en la Revista lafinoumericana de sociologia (1969). El concepto de la exclusión social ha sido utilizado en distintas publicaciones de la Organización Internucional did Trabajo (OIT) como instrumento para analizar los problemas del empleo en los países industrializados; sólo recientemente se ha abordado el problema de sus ventajas telativas para la comprensión de la realidad actual latinoamericana (véase Barros, De los Rios y Torche, 1996).

${ }^{24} \mathrm{La}$ investigacion sobre "Los asentamientos irregulares en Montevideo" realizada por la Consultora Datos para el Ministerio de Viviendil, Ordenamiento Territorial y Medio Ambjente, intenta una clasificación de los asentamientos según su nivel de integración con la sociedad global, utilizando como criterio la asistencia de los niños a la enseñanza primaria. El criterio parece adecuado dado que en Ur'ıguay la no asistencia de un niño a la escuela indica una clara
}

Como dice el sociólogo Castagnola en un artículo reciente publicado en la Revista Tres, "los guetos montevideanos son barrios de formación muy reciente, en los que abundan las carencias, y la pobreza convive con la delincuencia" (Castagnola, 1996, p. 68).

En los guetos se dan condiciones favorables a un progresivo deterioro del capital social de los pobres. Ese capital social se refiere a las normas de convivencia, a la confianza mutua y a las redes de reciprocidad que facilitan que cada familia pueda responder con la ayuda de otros a las situaciones de crisis. Pero en los guetos la situación no parece permitirlo. En primer lugar, los asentamientos precarios están cada vez más aislados del mundo exterior: la prensa informa de casos en los cuales ni la policía ni las ambulancias se atreven a entrar en ellos. Segundo, la prensa presenta también declaraciones de personas que no pueden salir de sus casas, que temen dejar solos a sus hijos, lo que refleja una ruptura de las normas básicas de convivencia dentro del gueto. ${ }^{25}$ Tercero, los que pueden migrar a otros barrios, que usualmente son los que tienen mayor capacidad de influir en las decisiones de las autoridades públicas, lo hacen, y así empobrecen aún más los recursos de la comunidad. El deterioro del capital social en los guetos urbanos se refleja entonces en al menos tres dimensiones: su creciente aislamiento con respecto a la sociedad global, el desgaste de la reserva de confianza entre los mismos vecinos y el continuo drenaje de los que "tienen voz".

La creciente homogeneización de las condiciones de precariedad entre los hogares que conviven en un mismo asentamiento; el débil y muchas veces conflictivo contacto con personas de distinta condición; la ausencia en el entorno inmediato de autoridades morales que puedan sancionar las conductas que se desvían de lo que prescriben los valores más generales de la sociedad, y la percepción de que son inaccesibles las vías legítimas para alcanzar las metas que la sociedad propone, son todos factores que contribuyen a un debilitamiento progresivo del contenido de normas y valores. Ese vacío normativo puede favorecer la emergencia de liderazgos que proponen un orden social

ruptura con los patrones de comportamiento socialmente aceptados. Utilizando ese criterio, la investigación encuentra que en el $35 \%$ de los asentamientos todos los niños asisten regularmente a la escuela, en el $58 \%$ lo hace la mayoría, pero no todos, y el $7 \%$ restante se divide entre aqueltos asentamientos en los que sólo asiste una minotráa y aquellos en que los nifíos no asisten.

${ }^{25}$ Vease algunos ejemplos de estas experiencias en El observador (1996), y los reportajes a dos jóvenes habitantes del barrio Borro en el semanario Búsqueda ( $1996 \mathrm{~b}$ y c). 
CUADRO IA

Montevideo: Estructura de la población de los asentamientos precarios, por sexo y tramo de edad, 1984-1994

\begin{tabular}{|c|c|c|c|c|c|c|}
\hline \multirow[t]{2}{*}{ Tramos de edad } & \multicolumn{2}{|c|}{ Hombres } & \multicolumn{2}{|c|}{ Mujeres } & \multicolumn{2}{|c|}{ Total } \\
\hline & 1984 & 1994 & 1984 & 1994 & 1984 & 1994 \\
\hline $\begin{array}{l}\text { Hasta } 10 \text { años } \\
11 \text { a } 18 \text { años } \\
19 \text { a } 40 \text { an̆os } \\
41 \text { a } 65 \text { aด็os } \\
66 \text { años y mas }\end{array}$ & $\begin{array}{r}32 \\
18 \\
30 \\
17 \\
3\end{array}$ & $\begin{array}{r}33.1 \\
19.7 \\
31.0 \\
14.1 \\
2.1\end{array}$ & $\begin{array}{r}36 \\
15 \\
33 \\
13 \\
3\end{array}$ & $\begin{array}{r}34.0 \\
20.9 \\
33.3 \\
10.5 \\
1.3\end{array}$ & $\begin{array}{r}35 \\
16 \\
31 \\
15 \\
3\end{array}$ & $\begin{array}{r}33.5 \\
20.3 \\
32.2 \\
12.3 \\
1.7\end{array}$ \\
\hline Total & 100 & 100.0 & 100 & 100.0 & 100 & 100,0 \\
\hline
\end{tabular}

Fuente: Cecilio, 1995.

enmarcado en una subcultura de la marginalidad y que legitiman patrones de conducta distintos, y muchas veces opuestos, al de la sociedad global. Tales liderazzos plantean costos y beneficios a la comunidad del zueto. El costo mayor es que el funcionamiento de la comunidad debe amoldarse a las exigencias de esos proyectos delictivos: distribución y comercialización de ; a droga (como en las favelas de Rio de Janeiro), "aguantadero" de delincuentes, "desguazadero" de iutomóviles, etc. Los beneficios son una convivencia más ordenada, cierta protección y la posibilidad de obtener, a través de la participación en esos negocios, ingresos que de otro modo serían de muy difícil acceso, especialmente para los jóvenes. Las lealtades así generadas aseguran la complicidad con las actividades ilegítimas que emprende el nuevo liderazgo.

Pero, como se mencionó anteriormente, la "guetización" es sólo un ejemplo extremo de un proceso general de segregación residencial que ocurre en todas las ciudades y que responde a la expansión de la lógica del mercado, uno de cuyos efectos es la pérdila de contacto cotidiano entre personas de distinta condición socioeconómica. El aislamiento se hace mayor cuando paralelamente a la segregación residencial se produce una segregación en los servicios de tsparcimiento, de salud y de educación.

\section{¿.. Segmentación en la educación}

Los pronunciamientos de las reuniones cumbres presidenciales de los últimos años parecen indicar que los rnáximos responsables de las políticas públicas están reconociendo que la equidad en los primeros años de vida debe formar parte del núcleo valórico de los rnodelos que orientan el desarrollo en América Latina, y que la concentración de los recursos de los sistemas educativos en los niños de hogares con bajos ni- veles socioculturales es uno de los medios más eficientes para quebrar los mecanismos de reproducción de la pobreza y la segmentación social. Paradojicamente, al mismo tiempo que se enuncian estos principios, muchas sociedades de la región están asistiendo a un proceso inédito de estratificación de los circuitos educativos. ${ }^{26}$ Parece evidente que mal puede estar habilitado el sistema educativo para contribuir a levantar la hipoteca social de pobreza y desigualdad, y para contrapesar la creciente segmentación laboral, si él mismo está segmentado. Ciertamente este es uno de los nudos principales del problema social contemporáneo en muchos países latinoamericanos.

Al respecto, es necesario tener en cuenta que fuera de los períodos de conscripción obligatoria en las fuerzas armadas - para los países donde esta obligación está vigente y su aplicación es efectivamente universal一, existen pocas instituciones de paso obligado para los ciudadanos que brinden a personas de distinto origen social la oportunidad de interactuar por tiempo prolongado sobre bases distintas al contrato de trabajo o al intercambio comercial de bienes y servicios. Sin duda, el sistema educativo es el principal -..y muchas veces el único-- ámbito institucional que puede actuar como lugar de fusión en que los niños y adolescentes pobres tengan la posibilidad de mantener una relación cotidiana y desarrollar códigos comunes y vínculos de solidaridad y afecto, en condiciones de igualdad, con sus pares de otros estratos. En este sentido, la contri-

\footnotetext{
${ }^{26}$ Tanto es así, que en algunos países de la región la conciencin de que tales circuitos existen hace que muchos padres vival una etapa de gran ansiedad tratando que ninhos de tres o cuatro años entren en determinado jardín de jnfantes (donde hasta se les toma examen de ingreso), porque esa incorporación los habilita posteriormente para continuar en un circuito educativo de escuelas y colegios con curerpos docentes y equipamientos pedagógicos de alta calidad, que a su vez les abrirá Jas puertas de las unejores universidades.
} 
bución de la experiencia estudiantil al enriquecimiento del capital social será mayor cuanto más grande sea la semejanza entre la comunidad escolar de cada establecimiento y la comunidad nacional. En cambio, a medida que se acentúa la segmentación entre establecimientos educativos, aumenta la probabilidad de que los iniembros de un estrato social sólo se encuentren en una relación cara a cara con miembros de otros estratos sociales en el mercado de trabajo, donde tales relaciones ya estarán enmarcadas en Jos patrones jerárquicos de la organización del mundo laboral. ${ }^{27}$

De no ser así, esto es, si los ricos van a colegios de ricos, si la clase media va a colegios de clase media y los pobres a colegios de pobres, el sistema educativo poco puede hacer para promover la integración social y evitar la marginalidad, pese a sus esfuerzos por mejcrar las oportunidades educativas de los que tienen menis recursos. ${ }^{28}$ Por ello es importante destacar no sólo la contribución a la equidad que hace el sistema educativo a través de una mayor igualdad de oportunidades, sino también su contribución a la integración de lé. sociedad, al promover la interacción entre desiguales en condiciones de igualdad.

Al facilitar dicha interacción, la educación puede promover una distribución más equitativa del capital socic.l. El capital social de un estudiante son sus expectativas legítimas de que otros lo ayudarán en el futuro. El valor de ese capital depende del número de personas dispuestas a proveer tal ayuda, de los recursos que puedan movilizar esas personas y del grado de obligación que sientan hacia él (Flap y Graaf, 1986). La ir teracción cotidiana en un mismo establecimiento educativo puede producir tales efectos porque:

i) genera sentimientos de pertenencia a una misma comunidad, con identidades compartidas y metas comunes, así como actitudes positivas de reconocimiento del otro como persona de derechos y también sentinientos de obligación moral que se extienden a compañeros de distinto origen social, religioso, étnico o nacional. Desde el punto de vista de la formación de la ciıdadanía, la importancia de esta experiencia es mayor cuanto más representativa de la comunidad

${ }^{27}$ Esta no parece haber sido la experiencia en el Uruguay, donde a través de la universalización de la escuela pública generalizada, el sistema educativo ha desempeñado un papel muy importante en el logro de un nivel de integración social que hoy día sigue siendo una característica distintiva del paśs en el marco regional.

${ }^{2 K}$ Esta afirmación es particularmente válida para sociedades donde os valores dominantes rechazan de manera explicita las barreras de zlase. nacional es la comunidad estudiantil de cada establecimiento;

ii) permite a estudiantes de determinado origen ampliar y profundizar su conocimiento del mundo, enriqueciéndolo con las experiencias de vida, códigos culturales, hábitos y costumbres de estudiantes de origen distinto;

iii) abre posibilidades de competir por méritos en un contexto donde supuestamente no operan influencias derivadas de la diferente situación socioeconómica de los estudiantes. Por ende, es un contexto favorable a la formación de la autoestima;

iv) sobre todo, permite a los estudiantes de escasos recursos establecer redes de reciprocidad y obligaciones, relaciones de confianza y lealtades con otros de hogares más acomodados. Estos contactos pueden ser de suma utilidad para una buena incorporación al mercado de trabajo, puesto que los más influyentes -aquéllos con más fácil acceso a las ocupaciones atractivas- tienen un conocimiento directo de los méritos de los menos influyentes y obligaciones derivadas de una historia común. Creer que únicamente los méritos van a ayudar a la movilidad social es una ficción que sólo se cumple en situaciones extraordinarias. Los contactos sociales, con todo lo que ellos implican, tienen una gran significación, tanto a nivel personal como a nivel social, para el aprovechamiento pleno del capital humano. Además, en la medida en que los contactos generan un razonable optimismo con respecto a conseguir empleos adecuados al nivel educativo que se alcance, las personas estarán más motivadas a invertir en el desarrollo de su capital humano;

v) ofrece a los padres de los estudiantes, independientemente de su situación económica, la oportunidad de interactuar con otros padres para resolver problemas de interés común. En este sentido, la migración de los más acomodados hacia la enseñanza privada im. plica la pérdida de un apoyo sustancial para elevar el nivel de los colegios públicos.

Dada la desigual capacidad que tienen padres de diferentes estratos socioeconómicos de costear los estudios de sus hijos, una señal de la segmentación educativa es la diferenciación entre enseñanza pública gratuita y privada paga. ${ }^{29}$ En Uruguay, esta diferencia ción ha cobrado relevancia recientemente. La gran mayoría de los actuales padres uruguayos de clase media provienen de la escuela pública y una porción de ellos

\footnotetext{
${ }^{29}$ No se consideraron las escuelas privadas gratuitas porque, según los datos de la Encuesta Continua de Hogares, sólo atienden a menos del $3 \%$ del alumnado urbano total.
} 
envía a sus hijos a la escuela privada. Es probable que ellos hayan tenido una experiencia directa con las bondades de la función integradora de la escuela pública, que se hayan esforzado porque se mantenga un nivel aceptable de calidad en ella, y que sólo por su deterioro evidente hayan tomado la decisión de enviar a sus hijos a la escuela privada y paga.

La información elaborada sobre la base de la Encuesta Continua de Hogares (cuadro 15) permite seguir la evolución del peso relativo de la educación primaria y secundaria de carácter privado y pago en el Uruguay urbano, así como sus efectos en las probabilidades de interacción cara a cara, en los establecimienos educativos, de estudiantes de origen socioecónonico distinto. ${ }^{30}$

A nivel de las áreas urbanas de todo el país, la ¿ducación pagada tiene una incidencia baja: menos de tho de cada cinco estudiantes en 1994.

Sin embargo, se registran sustanciales diterencias intre Montevideo y el interior urbano. Mientras en la capital la relación es ligeramente mayor a uno de cada rres estudiantes, en el interior es aproximadamente de uno de cada 16 estudiantes.

En Montevideo, la proporción de estudiantes que pagan por sus estudios experimentó entre 1984 y 1994 pequeños pero sistemáticos incrementos en todos los niveles de enseñanza. En el interior urbano, en cambio, la muy incipiente privatización de la enseñanza no fiene una tendencia defïnida: se elevó en 1989 para descender en 1994.

Cuando se analizan los datos tomando en cuenta cl ingreso de los hogares de los estudiantes se observa que en Montevideo, sólo uno de cada cuatro estudianIes del estrato alto asistía en 1994 a la enseñanza priunaria o al ciclo básico de la enseñanza secundaria que se brindaba en establecimientos públicos. Una proporción mayor lo hacía en el bachillerato público (segundo ciclo de la enseñanza secundaria). La privatización (le la enseñanza en estos estratos se aceleró en el peIíodo 1989-1994. Aun cuando todavía incipiente, existe an Montevideo una clara tendencia hacia la segmentación del sistema educativo. En el interior urbano, en

\footnotetext{
3' La diferenciación entre enseñanza gratuita y paga debilita la funciớn integradora si significa una división en términos de los ingresos de los hogares. Para examinarla, se clasiticó a los estudiantes en tres grupos de acuerdo al ingreso per cápita de sus hogares: se denominó estrato bajo al $30 \%$ de menores ingresos; estrato medio al $40 \%$ siguiente y estrato alto al $30 \%$ de mayores ingresos. El ejercicio se propuso obtener una primera aproximación a los canbios a través del tiempo en la probabilidad de interacción cara a cara entre estudiantes de distinto origen socioeconómico.
}

cambio, y pese al incremento de la privatización, hasta 1994 la gran mayoría de los estudiantes en mejor posición económica seguía concurriendo a establecimientos públicos.

En el mismo cuadro 15 se puede apreciar una transferencia de estudiantes del ciclo básico privado al bachillerato público. Pero las posibilidades de interacción entre adolescentes de distinto origen socioeconómico no parecen aumentar con ello. El desgranamiento escolar es mayor en los estratos más bajos y, por ende, las oportunidades mayores de interacción entre estudiantes de estratos socioeconómicos distintos se dan en la enseñanza primaria y el ciclo básico de la secunda. ria. En rigor, y como se puede apreciar en el cuadro 16 , menos de la mitad de los jovenes de menores recursos que tienen entre 16 y 18 años —edad en la que se concentran los estudiantes del segundo ciclo de secundaria- asisten a establecimientos de enseñanza. ${ }^{31}$

La tendencia a la privatización de la enseñanza es un fenómeno que afecta a la gran mayoría de los países de la región. Cuanto más acentuada es la segmentación por clases, más difícil se hace revertirla. En Uruguay, sin embargo, el peso ideológico relativamente alto que parece tener la educación pública en la generación que hoy día envía sus hijos a escuelas y colegios, permite alentar la esperanza de que el eventual éxito de las reformas educativas que se plantean en la aclualidad puedan frenar este proceso o cambiar su signo.

Es conveniente subrayar, por un lado, que la privatización de la enseñanza es sólo una expresión de la segmentación social y de la heterogeneidad en la calidad de las oportunidades educativas $y$, por otro, que todo intento de acercarse a la magnitud exacta del problema deberá analizar otras formas de diferenciación, tanto entre establecimientos privados como entre establecimientos públicos y gratuitos. Ya la tendencia a la segregación residencial en Montevideo permite presumir que el sector público puede estar reproduciendo esa segmentación. Sin duda también allí funcionan mecanismos que concentran los profesores más experimentados, la infraestructura más completa y la mejor dotación pedagógica en los establecimientos a los que concurren los estudiantes de estratos más altos $y$, viceversa, el personal con menor experiencia, las

\footnotetext{
31 El cuadro también pertnite apreciar que mientras la participación en el segundo ciclo de enseñanza secundaria de los jovenes de menores recursos disminuye ligeramente en el período considerado, to contrario sucede con los jóvenes de los estratos de ingreso más alto.
} 
CUADRO is

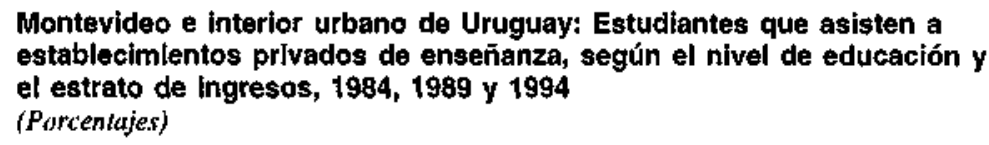

\begin{tabular}{|c|c|c|c|c|c|c|c|c|c|}
\hline \multirow{2}{*}{$\begin{array}{l}\text { Estratós } \\
\text { de ing resos }\end{array}>_{\text {educación }}^{\text {Nivel de }}$} & \multicolumn{3}{|c|}{ Primaria } & \multicolumn{3}{|c|}{ Ciclo secundario básico } & \multicolumn{3}{|c|}{ Bachillerato: } \\
\hline & 1984 & 1989 & 1994 & 1984 & 1989 & 1994 & 1984 & 1989 & 1994 \\
\hline \multicolumn{10}{|l|}{ Montsvideo } \\
\hline Bajo & 6.7 & 8.7 & 11.1 & 8.7 & 8.4 & 11.0 & 2.3 & 11.0 & 6.4 \\
\hline Medi, & 22.0 & 32.8 & 44.9 & 23.0 & 26.8 & 32.1 & 16.2 & 18.9 & 25.4 \\
\hline Alto & 56.5 & 62.7 & 73.6 & 51.9 & 58.1 & 78.3 & 40.2 & 40.0 & 58.4 \\
\hline Total & 20.2 & 22.6 & 29.0 & 24.8 & 26.2 & 29.3 & 22.3 & 24.3 & 29.7 \\
\hline \multicolumn{10}{|l|}{ Interior urbano } \\
\hline Bajo & 2.1 & 3.2 & 2.6 & 1.5 & 1.9 & 1.9 & - & 1.6 & - \\
\hline Medii) & 7.3 & 12.2 & II.] & 5.1 & 7.7 & 7.4 & 2.0 & 4.2 & 2.5 \\
\hline Alto & 18.3 & 24.6 & 26.6 & 13.0 & 18.8 & 18.1 & 1.1 & 5.9 & 8.6 \\
\hline Total & 6.7 & 8.2 & 7.7 & 5.8 & 7.7 & 6.5 & 1.2 & 4.0 & 3.2 \\
\hline
\end{tabular}

Fuente: Elaboración propia sobre la base de las Encuestas Continuas de Hogares del INE.

"Cik lo secundario superior.

CUADI:O I6

Montevideo e interior urbano de Uruguay: Población de 16 a 18 años que no asiste a establecimientos de enseñanza, según el estrato de ingresos, 1984, 1989 y 1994

\begin{tabular}{|c|c|c|c|c|c|c|}
\hline \multirow[b]{2}{*}{ Años } & \multicolumn{3}{|c|}{ Montevideo } & \multicolumn{3}{|c|}{ Interior urbano } \\
\hline & Bajo & Medio & Alto & Bajo & Medio & Alto \\
\hline 1984 & 51.1 & 26.6 & 15.4 & 60.4 & 39.1 & 30.1 \\
\hline 1989 & 51.6 & 28.3 & 14.4 & 56.8 & 44.0 & 27.6 \\
\hline 1994 & 53.1 & 26.9 & 11.3 & 58.0 & 43.1 & 27.1 \\
\hline
\end{tabular}

Fuenta: Elaboración propia sobre la base de las Encuestas Continuas de Hogares del INE.

instalaciones más inadecuadas y el equipamiento pedagógico más rudimentario en las zonas rurales o en los barrios marginales de las ciudades (CEPAL, 1990b, 1992 y 1994).

Dado que los padres muestran una tendencia natural a enviar a sus hijos a los mejores colegios, tanto en lo que hace a la calidad de la enseñanza como en cuanlo a su acuerdo con la filosofía que la orienta, todo intento de mezclar niños y adolescentes provenientes de distintos estratos sociales se convierte en un área dura de política. Bajo estas circunstancias, las acciones educativas que promuevan la cohesión social deberár atender al delicado equilibrio que supone, por un lado, asumir la responsabilidad del Estado de reforzar los mecanismos de integración social y, por otro, res- petar el derecho de los padres a enviar a sus hijos a los establecimientos que les garanticen Ia mejor educación posible. Restablecer el prestigio de la escuela pública, haciendo más atractiva su oferta, es una de las salidas, aunque ciertamente no la única. Cualquiera sea la solución, seguramente exigirá inversiones adicionales en la educación pública y decisiones de redistribución sectorial del gasto. Si se tiene en cuenta que a medida que se acelere la incorporación de cambios tecnológicos el eje de la integración social pasará más y más por el sistema educativo, los costos que se asuman para reforzar esa función integradora deberán balancearse con los considerables costos que deberá afrontar la sociedad como consecuencia de la creciente estratificación de los circuitos educativos. 


\section{VII}

\section{Conclusiones}

\section{Síntesis del marco conceptual y metodológico}

Las dimensiones de la marginalidad son muchas y el conocimiento disponible insuficiente para proponer una respuesta global al problema. Lo que se busca en este trabajo es sugerir orientaciones que permitan bloquear algunas rutas importantes a la marginalidad del futuro. Para ello se han explorado las causas inmediatas de la marginalidad en la pobreza urbana, esto es, las condiciones en las cuales el comportamiento de un segmento de los pobres comienza a apartarse de los patrones socialmente aceptables. Una señal extrema de esta ruptura son los comportamientos delictivos.

Como la mayoría de los fenómenos sociales, la marginalidad responde a múltiples factores, cuyos efectos se refuerzan recíprocamente de manera cíclica. El esquema utilizado para explicar la marginalidad se ha centrado en el desajuste entre metas legítimas, estructuras de oportunidades y capacidades diferentes para hacer uso de medios legítimos. Se ha puesto el acento en los procesos que están afectando la formación de esas capacidades en los estratos bajos urbanos.

En la secuencia de hechos que conducen a la marginalidad se ha prestado particular atención a las consecuencias de la tensión entre la estructura de oportunidades y la formación de capacidades, que impacta especialmente a adolescentes y jóvenes pobres. Por un lado, los niveles de calificación que se exigen a los jóvenes para acceder a un empleo productivo son cada vez más altos, lo que por lo general los obliga a postergar su entrada al mercado de trabajo y permanecer por más tiempo en las instituciones de enseñanza. Por otro, hay un debilitamiento progresivo de las familias que reduce de manera significativa su aptitud para proveer por un tiempo prolongado los activos materiales, emocionales, de conocimiento, culturales, de hábitos de disciplina, simbólicos y sociales, que capacitarían a los menores para extender y profundizar su formación utilizando los canales existentes. Esta falta de correspondencia entre la estructura productiva y las estructuras familiares es una fuente importante de marginalidad. A su vez, algunos cambios en la estructura social, en particular las tendencias al aislamiento social de los pobres vinculadas a la segregación residencial y la segmentación de los servicios (en particular, los educativos), contribuyen a consolidar patrones subculturales de marginalidad.

\section{Síntesis de los hallazgos}

Las encuestas de opinión revelan que los uruguayos perciben un aumento de la delincuencia. En una proporción significativa de casos esa percepción deriva de haber sido víctima de un delito, o de haberlo sido familiares o amigos. Es también significativo el porcentaje de personas que declara tener poca o ninguna confianza en la policía y el poder judicial. No es de extrañar entonces que muchos uruguayos manifiesten sentimientos de inseguridad y tengan comportamientos inducidos por el temor al crimen y la violencia. Si bien es probable que la resonancia en la opinión pública de los medios de comunicación pueda estar magnificando indebidamente las dimensiones de los crímenes, la información que entregan los registros estadísticos de criminalidad, las experiencias de victimización que recogen las encuestas de opinión, así como la confianza relativamente baja en los organismos de control de la delincuencia, justifican que aumente el sentimiento de inseguridad.

La evolución de los delitos no está asociada, al menos en el período considerado, a las variaciones en los índices de pobreza. Esto es, los robos y las rapiñas aumentaron pese al descenso observado en ta propor* ción de hogares cuyos ingresos nos les permiten cubrir el costo de una canasta básica de consumo.

El descenso de la pobreza puede ir acompañado de una elevación de las aspiraciones, ya sea porque aumentan los estándares generales de consumo de la sociedad, o porque se eleva la exposición de los pobres a dichos estándares. Posiblemente ambas cosas estén sucediendo en el Uruguay, pues en esa đirección operan los efectos de la creciente globalización y penetración de los medios de comunicación en los hogares. ${ }^{32}$ Para muchos jóvenes de los estratos bajos urba-

\footnotetext{
${ }^{32}$ No hay información dispotible sobre el aumento de la exposicion de los pobres a las propuestas de consumo de la sociedad global. Un indicador aproximado a dicha exposición sería el porcentaje de hogares pobres que tienen equipos de televisión. Pero la recolección de esa información en las encuestas de hogares es demasiado reciente (1991) como para permitir comparaciones significativas. Por otra parte, una señal gruesa de los cambios en los patrones generales de consumo está dada por una combinación del aumento del consumo global y de las varjaciones en el peso de los gastos de alimentos en dicho consumo global. El aumento del consumo entre 1982 y 1994 fue de $18 \%$ y la proporción de los alimentos en dicho consumo bajó del $31 \%$ al $28 \%$.
} 
nos, la exposición al mundo rutilante que publicitan esos medios amplía sus espacios de frustración, y la deliniuencia puede parecer la única vía de sortearlos.

Otra alternativa apunta al hecho de que el aumento de lass exigencias para acceder a los canales legítimos de movilidad social no hayan ido acompañados de formación de capacidades para hacer uso de ellos. La información presentada en el documento lleva a sospechar que esta última alternativa es la que tiene mayor peso en la explicación de los comportamientos marginales entre los pobres urbanos.

Zntre los datos presentados están los que se refieretı a las características de los hogares de los menores internados en el INAME por infracción o inconducta social. La mitad de esos menores nacieron fuera del matrimonio, y solamente en un cuarto de sus grupos de convivencia figuran ambos padres biológicos. El aumento sustancial de las tasas de ilegitimidad y de las uniones consensuales entre los jóvenes (particularmente entre los de baja educación) que se ha producido en los últimos quince años, permite suponer que los cambios en las formas de constitución y en la estabilidad de las familias pobres han de ser una de las fuentes más impotantes de la marginalidad futura.

L_a creciente tendencia a la constitución de hogares incompletos y de parejas inestables en los estratos bajos urbanos implica un progresivo debilitamiento de la farnilia y, por ende, de su aptitud para proveer los activos con que los niños y adolescentes pobres van capacitándose para hacer uso de la estructura de oportunidades existente en la sociedad. En la génesis de las dificultades para constituir familias estables se observa una combinación de cambios culturales en el significado de la sexualidad, y de renuencia de los varones a asumir los compromisos que implican la formación $\mathrm{y}$ el inantenimiento de un hogar. En efecto, los datos revelian, por un lado, un descenso en las edades de iniciación sexual y un aumento de la proporción de madres indolescentes en el total de nacimientos. Por otro, son muy altos los niveles de logros educativos a partir de los cuales es posible obtener los ingresos necesarios jara que un joven pueda mantener una familia mínima.

zos datos presentados sobre el aumento de la segregación residencial y de la segmentación educacional, por último, muestran un progresivo aislamiento sorial de los pobres. La carencia de modelos apropiadcs y el alejamiento de los ejemplos exitosos de asociación entre esfuerzos y logros genera un contexto favorable al desarrollo de una subcultura de la marginalidad.

\section{Orientaciones para la acción}

Los mecanismos que conducen a que las personas se aparten de los patrones de conducta socialmente aceptados comienzan a funcionar en la temprana infancia y se van consolidando a través de las etapas del ciclo de vida. En este sentido, se puede hablar de rutas a la marginalidad. Toda política de integración social se propone bloquear esas rutas y crear condiciones que favorezcan el restablecimiento de vínculos de las personas con la sociedad. Para ello, las acciones deben apoyarse en un diagnóstico que permita identificar los mecanismos que operan en distintos momentos de la vida de las personas, evaluar el impacto relativo de cada uno de ellos en la propensión a conductas marginales, y seleccionar entonces puntos cruciales de intervención sobre la base del costo-beneficio de cada medida. Sólo una visión del conjunto de los mecanismos actuantes permitirá escoger racionalmente las alternativas más eficaces y eficientes. ${ }^{33}$

Pese a que el debilitamiento de las instituciones primordiales (familia y comunidad) parece estar en el origen de las señales de deterioro que aparecen en el tejido de la sociedad uruguaya, los problemas vinculados con la constitución y la estabilidad de las familias no están en el centro de atención de las políticas sociales. Para acrecentar la eficacia y la eficiencia de la política social ese desajuste debe corregirse.

Un primer paso ineludible es atacar el problema de la invisibilidad estadística del tema. Los datos publicados sobre ilegitimidad de nacimiento en el Uruguay llegan a 1989. Además, no se sabe nada sobre la proporción de niños que no viven con ambos padres biológicos, pese a la evidencia acumulada en países

\footnotetext{
${ }^{13}$ Los factores determinantes de la marginalidad que se analizaron en el artículo parecen actuar con relativa independencia de condicionamientos políticos y económicos. El hecho de que no se examinaran dichos condicionamientos no significa ignorar su influjo en la generación de marginalidad. Por ejemplo, no se puede desconocer que el restablecimiento de la democracia en el Uruguay y la consecuente reimplantación de los derechos ciudadanos han creado un escenario favorable para ta acción de los mecanismos de integración social. Tampoco se puede desconocer la importancia que tienen los recursos generados por el crecimiento económico sostenido en la lucha contra la pobreza y la inarginalidad y en la capacidad de la sociedad para crear espacios que faciliten la acción de las fuerzas integradoras. Pero es igualmente claro que los problemas de marginalidad e integración social se están volviendo a plantear aun en países de vieja y exitosa industrialización y con democracias antiguas y estables, to que sugiere la acción de causas más complejas que el ritmo de crecimiento económico o la consolidación de las democracias, y relativamente independientes de estas variables.
} 
desarrollados sobre los importantes efectos de las familias reconstituidas sobre los niños. Tampoco es posible ponderar la proporción de los núcleos familiares que por distintas razones no han logrado formar hogares autónomos. Es preciso, por lo tanto, reforzar las estadísticas vitales y efectuar pequeñas modificaciones en los cuestionarios de las encuestas de hogares y de los censos.

Un segundo campo de acción importante es el de sensibilizar a la conciencia pública de que cualquier opción institucional diseñada específicamente para compensar las falencias familiares será más difícil, más costosa y de menor eficiencia relativa que los esfuerzos por apuntalar a las familias. Es igualmente importante tomar conciencia de que los costos de tales opciones serán mayores mientras más se prolongue el período de formación necesario para que los jóvenes puedan satisfacer las nuevas exigencias del mercado de trabajo, dado que la familia parece ser insustituible como proveedora del apoyo material, psicológico, emocional, de hábitos de disciplina, etc., que demandan los nuevos patrones de integración social.

Una tercera esfera de acción es la de prevención de los embarazos adolescentes. Los datos reseñados en este artículo sugieren que es muy difícil evitar la acumulación de desventajas a lo largo de la vida cuando el punto de partida es débil y que, por ende, el momento de constitución de las familias es una de las instancias cruciales de intervención. Dado el creciente peso de los embarazos adolescentes y de su correspondiente participación en el aumento de las tasas de ilegitimidad, parece imprescindible crear condiciones favorables a la postergación de la edad de los embarazos. Esto apunta, entre otras cosas, a la necesidad de aplizar medidas en materia de educación sexual, impartiento conocimientos que permitan controlar la reproducsión y garantizar que se tendrán los hijos cuando se deseen, y que faciliten una comprensión más amplia y profunda de las responsabilidades de la maternidad y la paternidad.

También es prioritario reducir la alta vinculación que hoy existe entre constitución de familia y pobreza, particularmente en lo que se refiere a los jóvenes de escasos logros educativos. Constituir una familia fuera de la pobreza debería ser una meta accesible para os jóvenes. Esto guarda relación con la creación de oportunidades de empleo productivo, con la flexibili:zación de las exigencias para acceder a dicho empleo, con el tipo y la cobertura de los beneficios asociados a la paternidad (asignaciones familiares, licencias maternales y paternales, etc.) y con la posibilidad de uti- lizar servicios que permitan compatibilizar el trabajo con la crianza de hijos. Además, tiene que ver especialmente con las políticas habitacionales, porque la esperanza de acceder a una vivienda suele articular y dar sentido a los esfuerzos de la pareja, que sabe que la posesión de ese bien es un colchón protector frente a contingencias económicas difíciles, reduciendo así la vulnerabilidad de la familia.

Pero además de accesible, la familia debe ser una meta deseable. Y para que lo sea, ante todo se debe promover un reconocimiento social de su importancia. Las sociedades tradicionales ritualizaban el acto de! matrimonio en celebraciones que abarcaban a las comunidades locales, demostrando así la importancia que le asignaban. Estos ritos se han debilitado y en algunos casos han perdido toda significación. Corresponde a los organismos responsables generar condiciones para dignificar las ceremonias en el registro civil.

La otra institución primordial que alimenta el capital social de las personas y sus familias es la comunidad local. El fortalecimiento de los lazos comunales debe ser un matiz siempre presente en el diseño de las políticas sociales sectoriales. Entre las opciones de ejecución de dichas políticas, debe elegirse aquella que promueva el diálogo, la dependencia mutua, el reforzamiento de los vínculos de solidaridad, la realización de emprendimientos conjuntos. Así, se enriquecen las redes de reciprocidad y de confianza. Cuanto más denso sea el tejido social comunal, mayor será su capacidad para hacer cumplir estándares de comportamiento con más eficacia y eficiencia que las burocracias estatales y los organismos especializados de control, Las políticas de descentralización contribuyen al fortalecimiento de las comunidades locales, por cuanto amplían las oportunidades de que ellas participen en la definición y aplicación de programas que afectan directamen. te las condiciones de vida de los potenciales beneficiarios y de ese modo incrementan la capacidad de las personas y los grupos de identificarse con metas colectivas y de mejorar su situación a través del esfuerzo conjunto.

Los procesos de segregación residencial y de segmentación de los servicios conducen a un progresivo aislamiento de los pobres, y con ello aumentan las probabilidades de que surjan comportamientos marginales y que cristalicen en subculturas. Una vez que estas subculturas se instalan, se van perdiendo los códigos de comunicación compartidos con la sociedad "integrada", y en ambos segmentos sociales se van consolidando prejuicios y estereotipos que acentúan las distancias y reducen gradualmente las oportunidades 
de in teracción que vayan más altá del mercado de trabajo $\supset$ de la compra y venta de bienes y servicios. En cambio, la interacción regular en condiciones de igualdad recrea y fortalece los códigos compartidos de comunización. Las políticas de integración, por lo tanto, deben dar prioridad a la generación de tales espacios de in eracción.
Las consideraciones anteriores deberían ser tenidas en cuenta en el diseño urbano, en las políticas de radicación de viviendas y en la concepción de los servicios públicos, en particular de la educación. Cuanto más avance la tendencia actual a la segregación residencial y a la segmentación de los servicios, mayor será el costo social de contrarrestar sus efectos.

\section{Bibliografia}

Barros. P., D. De los Ríos y F. Torche (1996): Lecturas sobre la ixclusion social, Documento No. 31, Santiago de Chile, Organización Internacional del Trabajo (orT), Equipo Técnico Auttidisciplinario (ETM).

Basáfie z. M., M. Lagos y T. Beltrán (1996): Reporte 1995: Encues1" Latino Barómetro, Santiago de Chile, mayo.

BUSQU.DDA (1996a): Encuesta de Vox-Opinión y Mercado, Montevideo, 16 de mayo.

(1996b): Montevideo, I de julio.

(1996c): Montevideo, 17 de julio.

Castag ola, J. L. (1996): Los guetos y las probabilidades, Revista Jres. Montevideo, II de mayo.

Cecilio, M. (1995): Relevamiento de asentamientos irregulares en Montevideo, Asentamientos irregulares. Montevideo, Ministerio de Vivienda, Ordenamiento Territorial y Medio Ambien(1).

CEPAl (Comisión Económica para América Latina y el Caribe) (1987): La reprodacción biológica y social de los hogares de Montevideo, LC/R.0597 (SEM.39/07)/Rev. I, Montevideo, (Oficina de la CEPAL en Montevideo.

(1990a): Encuesta para un diagnóstico de la edacación tásica en Uruguay, Montevideo, Oficina de la CEPAL en Montevideo.

(1990): Qué aprenden y quiénes aprenden en las escuelas de Uruguay: hos contextos sociales e institucionales de exitos y fracasss, LC/MVD/R.58, Montevideo, Oficina de la (EPAL, en Montevideo.

(1991): Equidad y pobreza en la sociedad uruguaya, Montevideo, Oficina de la CEPAL en Montevideo, abril.

(1992): ¿Aprenden los estudiantes en el ciclo brisico de éducution media?, LC/MVD/R.78, Montevideo, Oficina de II CEPAL en Montevideo.

(1994): Los bachilleres uruguayos: quiénes son, qué aprenc'ieron y qué opinan, LC/MVD/R.12I, Montevideo, Oficina ce la CEPAL en Montevideo.

(1995): Panorama social de América Latina 1995, I.C/G.1886-P, Santiago de Chile. Publicación de las Naciores Unidas, No, de venta S.95.Il.G.17.

Dafoe Whitehead, B. (1993): Dan Quayle was right, The Atlantic Monthly, Nueva York, abtil.

El obsirvador (1995): Encuesta de equipos consultores, Montevicieo, 29 de febreto.

(1996): Vivir en la orilla, Montevideo, 4 de mayo.

El paí" (1995): Encuesta de CIFRA/González, Raga y Asociados, Montevideo, 18 de junio.

(I996a): Encuesta de CIFRA/Gonzflez, Raga y Asociados, Montevideo, 5 de mayo.

(1996b): Montevideo, 25 de mayo.

Filgueica, C. (1996): Sobre revoluciones ocultas: Ia familia en Urasuay, LC/MVD/R.14I/Rev. I, Montevideo, Oficina de la C.EPAL en Montevideo.
Flap, H.D. y N.D.Graaf (1986): Social capital and attained occupational status, The Netherland Journal of Sociology. No. 22, Amsterdaun.

González, L.E. (1995): El 80\% de los uruguayos cree que aumentó la violencia, El país, Montevideo, 18 de junio.

Guemberena, L. y ottos (1989): La gestación en la adolescencia. Hipótesis y conclusiones preliminares, Montevideo, Centro Latinoamericano de Perinatología y Desarrollo Humano (CLAP)/Organización Panamericana de la Salud (OPS)/Ministerio de Salud Pública.

Hirschi, T. y H.C. Selvin (1967): Delinguency Rerearch, Nueva York, The Free Press.

INE (Instituto Nacional de Estadísticas) (1996): Cuantificación de la pobreza por el método del ingreso para el Uruguay urbano, documento presentado al Taller regional de Expertos sobre Medición de la Línea de Pobreza en Uruguay (I2 y 13 de marzo), Programa para el Mejoramiento de los Sistemas de Información Socioeconómica en el Uruguay, Santiago de Chile, INE/Banco Interamericano de Desarrollo (BID)/CEPAL.

Instituto Nacional de Alimentación (INDA) (1989): Nutrición y embarazo en el Uruguay. Montevideo.

Irarrázaval, I. (1995): Habilitación, pobreza y política social. Estudios públicos, No. 59, Santiago de Chile, Centro de Estudios Públicos (CEP), invierno.

Katzman, R. (1992): ¿Por qué los hombres son tan irresponsables?, Revista de la CEPAL, No. 46, LC/G.177I-P, Santiago de Chile, CEPAL.

Klein, D. (1994): Tinta roja: efectos de la crónica policial en Uruguay. Montevideo, Rosebud Ediciones.

Murray, C. (1993): Política social y marginalidad; algunas lecciones de la experiencia norteamericana. Estudioss públicoss, No. 52, Santiago de Chile, CEP, primavera.

Revista latinoumericana de sociologia (1969): vol, 5, No. 2, Buenos Aires, Instituto Torcuato Di Tella.

Universidad de la República, Facultad de Medicina, Departamento de Psicología Médica (1996): Cuidando el potenciat del futuro: el desarrollo de niños preescolares en familias pobres de Uruguaty, Montevideo.

UNRISD (Instituto de Investigaciones de las Naciones Unidas para el Desarrollo Social) (1995); States of Disarray: The Social Effects of Globalization, Ginebra.

Uruguay. Ministerio de Educación y Cultura, Instituto Nacional de Ia Faunilia y de ta Mujer (1995); Uruguay adolescente: maternidad adolescente y reproducción intergeneracional de la pobreza. Montevideo.

Uruguay, Ministerio de Salud Pública, División de Estadística (1993): Estadísticas vitales del INE, Montevideo.

Uruguay, Ministerio de Vivienda, Ordenamiento Territorial y Medio Ambiente (1995): Los asentamientos irregulares en Momtevideo, Montevideo.

Wilson, J. (1994): Los valores familiares y el papel de la mujer, Facetas. No. 1, Washington, D.C. 